\title{
External Quality Assurance Project Report for the National Atmospheric Deposition Program's National Trends Network and Mercury Deposition Network, 2017-18
}

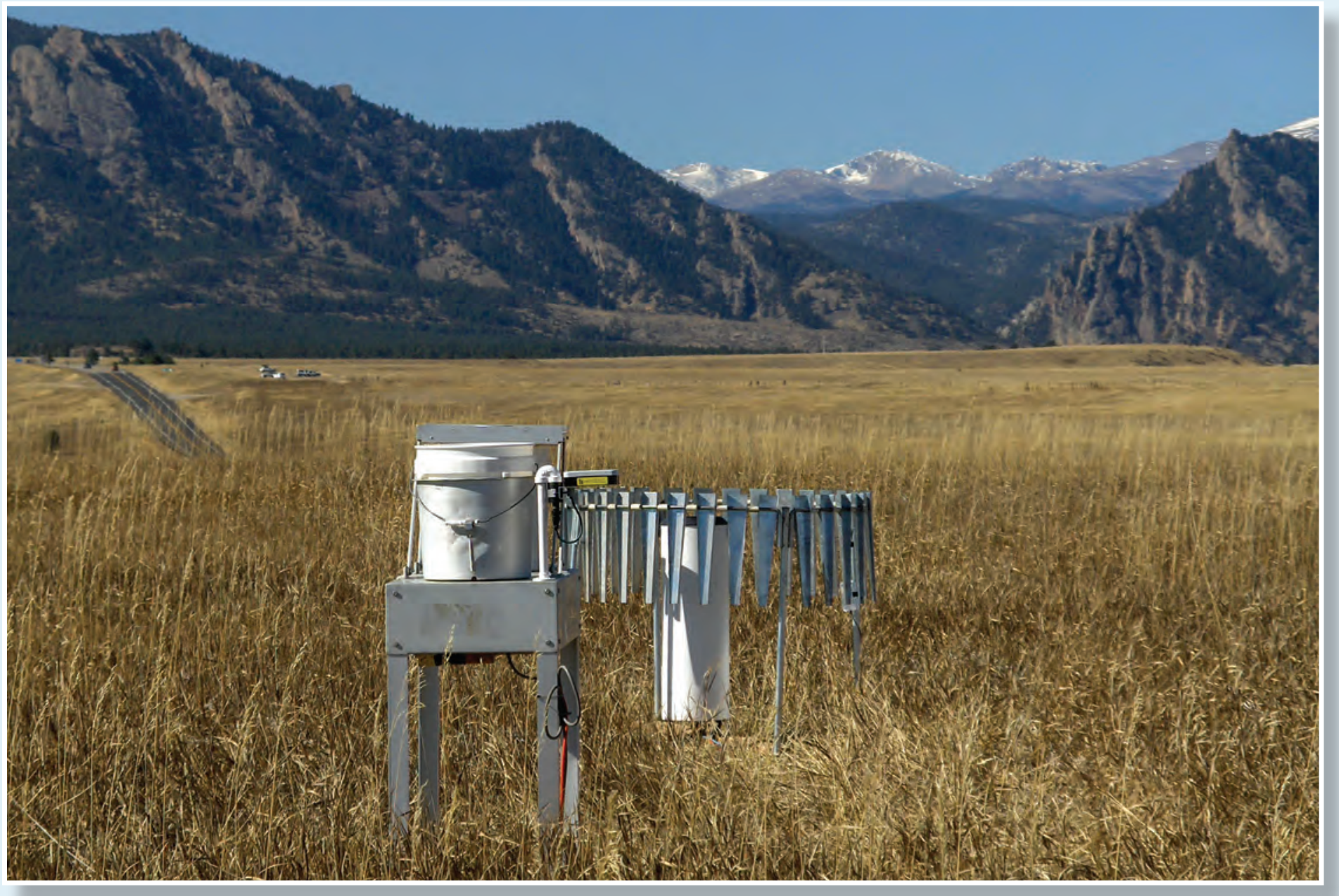

Scientific Investigations Report 2020-5084 
Cover. National Atmospheric Deposition Program, National Trends Network sites C086, Rocky Flats National Wildlife Refuge, Jefferson County, Colorado. (Photograph taken by Gregory A. Wetherbee, U.S. Geological Survey) 


\section{External Quality Assurance Project Report for the National Atmospheric Deposition Program's National Trends Network and Mercury Deposition Network, 2017-18}

By Gregory A. Wetherbee and RoseAnn Martin

Scientific Investigations Report 2020-5084 


\title{
U.S. Department of the Interior \\ DAVID BERNHARDT, Secretary
}

\author{
U.S. Geological Survey \\ James F. Reilly II, Director
}

U.S. Geological Survey, Reston, Virginia: 2020

For more information on the USGS - the Federal source for science about the Earth, its natural and living resources, natural hazards, and the environment—visit https://www.usgs.gov or call 1-888-ASK-USGS.

For an overview of USGS information products, including maps, imagery, and publications, visit https://store.usgs.gov/.

Any use of trade, firm, or product names is for descriptive purposes only and does not imply endorsement by the U.S. Government.

Although this information product, for the most part, is in the public domain, it also may contain copyrighted materials as noted in the text. Permission to reproduce copyrighted items must be secured from the copyright owner.

Suggested citation:

Wetherbee, G.A., and Martin, R., 2020, External quality assurance project report for the National Atmospheric Deposition Program's National Trends Network and Mercury Deposition Network, 2017-18: U.S. Geological Survey Scientific Investigations Report 2020-5084, 31 p., https://doi.org/10.3133/sir20205084.

Associated data for this publication:

Wetherbee, G.A., 2020, U.S. Geological Survey Precipitation Chemistry Quality Assurance Project Data 2017-2018:

U.S. Geological Survey data release, https://doi.org/10.5066/P9ZKXD8N.

Wetherbee, G.A., 2019, Data for the U.S. Geological Survey Precipitation Chemistry Quality Assurance Project for the National Atmospheric Deposition Program, 1978-2017: U.S. Geological Survey data release, https://doi.org/10.5066/ P94RC4GD.

ISSN 2328-0328 (online) 


\section{Contents}

Abstract

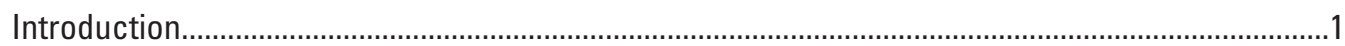

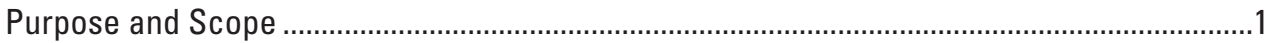

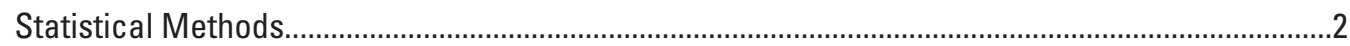

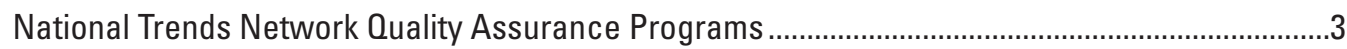

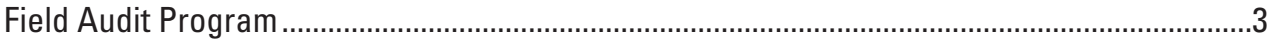

Network Maximum Contamination Levels................................................................................

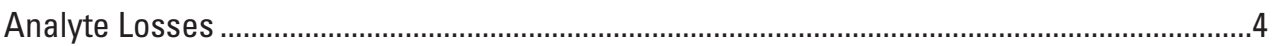

National Trends Network Interlaboratory Comparison Program..............................................4

Interlaboratory Comparison Program Bias and Variability....................................................

Interlaboratory Comparison Program Control Charts..................................................................7

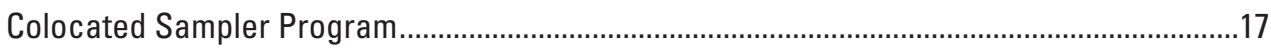

Mercury Deposition Network Quality Assurance Programs.........................................................22

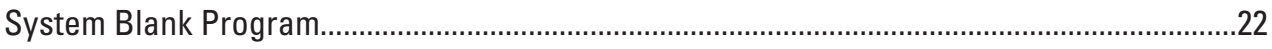

Network Maximum Contamination Levels for Mercury ........................................................2

Mass of Mercury Contamination ..................................................................................25

Mercury Deposition Network Interlaboratory Comparison Program ....................................25

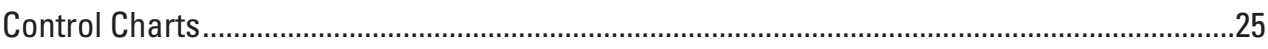

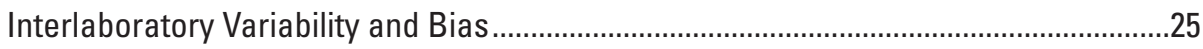

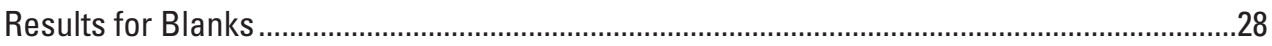

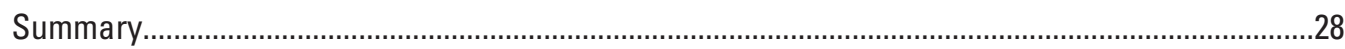

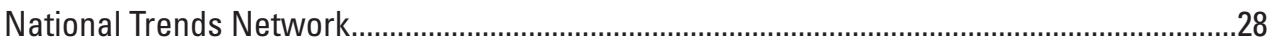

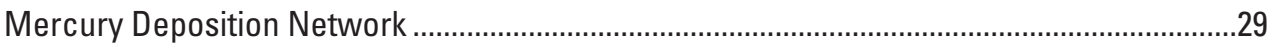

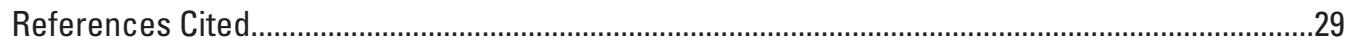

\section{Figures}

1. Graph showing distributions of upper confidence limits for sodium contamination concentrations measured by the field audit program, 2016-18 .................5

2. Graph showing network maximum contamination levels for National Trends Network analytes calculated using 3-year moving increments, 1997-2018..

3. Graphs showing maximum loss of hydrogen ion and ammonium and nitrate from weekly National Trends Network samples calculated using 3-year moving increments, 1997-2018.

4. Graphs showing differences between concentration values reported by the Central Analytical Laboratories and the median concentration values for all participating laboratories in the interlaboratory comparison program for the National Trends Network, 2017-18

5. Graph showing differences between total mercury concentrations reported by the Mercury Analytical Laboratory, Eurofins Frontier Global Sciences, Inc., and the median concentration values for all participating laboratories in the interlaboratory comparison program for the Mercury Deposition Network, 2017-18....26 


\section{Tables}

1. National Atmospheric Deposition Program's National Trends Network method detection limits, network maximum contamination levels, and analyte losses estimated from field audit samples in addition to calculated concentration quartiles for all valid monitoring data, 2015-18 .

2. Analyte most probable values for synthetic precipitation solutions used in the 2017-18 National Trends Network interlaboratory comparison program. .8

3. Analytical detection limits for laboratories participating in the U.S. Geological Survey interlaboratory-comparison program for the National Atmospheric Deposition Program, 2017-18.

4. Median differences between reported constituent concentrations and most probable values for synthetic wet-deposition samples, 2017 interlaboratory comparison program.

5. Median differences between reported constituent concentrations and most probable values for synthetic wet-deposition samples, 2018 interlaboratory comparison program.

6. Number of analyte determinations greater than the method detection limits for deionized water samples, 2017-18

7. Number of analyte determinations outside $\pm 3 f$-pseudosigma statistical control limits, by participating laboratory, 2017-18.

8. Overall median relative bias and sign test results for comparison of 75 National Atmospheric Deposition Program split samples analyzed by the former Central Analytical Laboratory at the Illinois State Water Survey (ICAL) and current Central Analytical Laboratory at the University of Wisconsin (WCAL).

9. Median weekly constituent concentration differences and annual deposition differences for colocated N-CON Systems Company, Inc. precipitation collectors at National Atmospheric Deposition Program sites CO11 and 11CO for all valid samples, water years 2017-18.

10. Event recorder data summary for colocated N-CON Systems Company, Inc., precipitation collectors at National Atmospheric Deposition Program sites C011 and 11C0, water years 2017-18

11. Three-year moving network maximum contamination levels and 90-percent upper confidence limits at the 50th, 75th, and 90th percentiles of total mercury contamination mass in system blank samples, 2004-17

12. Most probable values for total mercury in four solutions and hydrochloric acid blank samples used for the U.S. Geological Survey Mercury Deposition Network interlaboratory comparison program, 2017-18

13. Differences between reported concentrations and most probable values for total mercury determinations, Mercury Deposition Network interlaboratory comparison program, 2017-18.

14. Number of total mercury determinations greater than the method detection limits for blank samples, Mercury Deposition Network interlaboratory comparison program, 2017-18. 


\section{Conversion Factors}

International System of Units to Inch/Pound

\begin{tabular}{|c|c|c|}
\hline Multiply & By & To obtain \\
\hline \multicolumn{3}{|c|}{ Length } \\
\hline centimeter $(\mathrm{cm})$ & 0.3937 & inch (in.) \\
\hline \multicolumn{3}{|c|}{ Volume } \\
\hline liter $(\mathrm{L})$ & 1.057 & quart (qt) \\
\hline milliliter $(\mathrm{mL})$ & 0.03381 & ounce, fluid (oz) \\
\hline \multicolumn{3}{|c|}{ Application rate } \\
\hline kilogram per hectare $(\mathrm{kg} / \mathrm{ha})$ & 0.8264 & pound per acre (lb/acre) \\
\hline \multicolumn{3}{|c|}{ Concentration } \\
\hline milligram per liter $(\mathrm{mg} / \mathrm{L})$ & $3.34 \times 10^{-5}$ & ounce per quart (oz/qt) \\
\hline nanogram per liter (ng/L) & $3.34 \times 10^{-11}$ & ounce per quart (oz/qt) \\
\hline microgram per liter $(\mu \mathrm{g} / \mathrm{L})$ & $3.34 \times 10^{-8}$ & ounce per quart (oz/qt) \\
\hline
\end{tabular}

Temperature in degrees Celsius $\left({ }^{\circ} \mathrm{C}\right)$ may be converted to degrees Fahrenheit $\left({ }^{\circ} \mathrm{F}\right)$ as

${ }^{\circ} \mathrm{F}=\left(1.8 \times{ }^{\circ} \mathrm{C}\right)+32$.

Temperature in degrees Fahrenheit $\left({ }^{\circ} \mathrm{F}\right)$ may be converted to degrees Celsius $\left({ }^{\circ} \mathrm{C}\right)$ as ${ }^{\circ} \mathrm{C}=\left({ }^{\circ} \mathrm{F}-32\right) / 1.8$.

\section{Supplemental Information}

Specific conductance is given in microsiemens per centimeter at 25 degrees Celsius $(\mu \mathrm{S} / \mathrm{cm}$ at $\left.25^{\circ} \mathrm{C}\right)$.

Concentrations of chemical constituents in water are given in either milligrams per liter (mg/L), micrograms per liter $(\mu \mathrm{g} / \mathrm{L})$ or nanograms per liter $(\mathrm{ng} / \mathrm{L})$.

$\alpha$, alpha, is the maximum probability of incorrect rejection of the null hypothesis.

$100(p)$ th is the percentile equal to 100 times a value of $p$, for example, $100 \times(.9)=90$ th percentile.

Absolute value of $x=|x|$, where $x$ takes the form of numerical values or algebraic expressions.

Study period, calendar year or water years 2017-18, depending on the program.

Water year (WY) is the 12-month period from 0ctober 1 through September 30 of the following year and is designated by the calendar year in which it ends. 


\section{Abbreviations}

\begin{tabular}{|c|c|}
\hline ACM & AeroChem Metrics Model 301 collector \\
\hline ACAP & Asia Center for Air Pollution Research \\
\hline AIRMoN & Atmospheric Integrated Research Monitoring Network \\
\hline AMEC & AMEC Foster Wheeler for 2014, formerly AMEC, Inc. in 2013 \\
\hline CAL & Central Analytical Laboratory \\
\hline CASIG & $\begin{array}{l}\text { Chinese Academy of Sciences, Institute of Geochemistry (People's Republic } \\
\text { of China) }\end{array}$ \\
\hline CIES & Carey Institute of Ecosystem Studies \\
\hline CVAFS & Cold vapor atomic fluorescence spectroscopy \\
\hline DASNCU & Department of Atmospheric Sciences, National Central University (Taiwan) \\
\hline ECST & $\begin{array}{l}\text { Environment and Climate Change Canada (formerly [2015-16] Environment } \\
\text { Canada) Science and Technology Branch }\end{array}$ \\
\hline ETI Noah IV & Environmental Technologies, Inc. Noah IV precipitation gage \\
\hline$f$-psig & $f$-pseudosigma \\
\hline FRL & Flett Research, Limited (Canada) \\
\hline HAL & Mercury Analytical Laboratory, Eurofins Frontier Global Sciences, Inc. \\
\hline $\mathrm{HCl}$ & hydrochloric acid \\
\hline $\mathrm{Hg}$ & mercury \\
\hline ICAL & Central Analytical Laboratory, University of Illinois, Illinois State Water Survey \\
\hline ISWS & Illinois State Water Survey \\
\hline IVL & IVL Swedish Environmental Research Institute (Sweden) \\
\hline LEEO & Quebec Laboratory for Environmental Testing (Canada), also known as OLET \\
\hline MDL & method detection limit \\
\hline MDN & Mercury Deposition Network \\
\hline MOECC & $\begin{array}{l}\text { Ministry of Environment and Climate Change-Dorset Chemistry } \\
\text { Laboratory (Canada) }\end{array}$ \\
\hline MPV & most probable value \\
\hline MRL & minimum reporting level \\
\hline NADP & National Atmospheric Deposition Program \\
\hline $\mathrm{N}-\mathrm{CON}$ & N-CON Systems Company, Inc. \\
\hline NILU & Norwegian Institute for Air Research (Norway) \\
\hline NIST & National Institute of Standards and Technology \\
\hline NMCL & network maximum contamination level \\
\hline Noah IV & Environmental Technologies, Inc. Noah IV precipitation gage \\
\hline
\end{tabular}


NRS U.S. Department of Agriculture Forest Service, Northern Research Station, Durham, New Hampshire

NSA North Shore Analytical, Inc.

NTN National Trends Network

PCQA Precipitation Chemistry Quality Assurance project

PO Program Office for National Atmospheric Deposition Program

$\mathrm{QA} \quad$ quality assurance

RTI Research Triangle Institute, International

RVP Readiness Verification Plan

UCL $\quad$ upper confidence limit

UNAM Universidad Nacional Autonoma de Mexico, Centro de Ciencias de la Atmosfera (University of Mexico, Center for Atmospheric Sciences, Mexico City, Mexico)

USGS U.S. Geological Survey

VITO Flemish Institute for Technological Research (Belgium)

WCAL Central Analytical Laboratory, University of Wisconsin, Wisconsin State Laboratory of Hygiene

WML U.S. Geological Survey Wisconsin Mercury Laboratory

WSLH Wisconsin State Laboratory of Hygiene, University of Wisconsin, Madison 



\title{
External Quality Assurance Project Report for the National Atmospheric Deposition Program's National Trends Network and Mercury Deposition Network, 2017-18
}

\author{
By Gregory A. Wetherbee and RoseAnn Martin
}

\section{Abstract}

The U.S. Geological Survey (USGS) Precipitation Chemistry Quality Assurance project (PCQA) operated five distinct programs to provide external quality-assurance monitoring for the National Atmospheric Deposition Program's (NADP) National Trends Network and Mercury Deposition Network during 2017-18. The National Trends Network programs included (1) a field audit program to evaluate sample contamination and stability, (2) an interlaboratory comparison program to evaluate analytical laboratory performance, and (3) a colocated sampler program to evaluate variability attributed to automated precipitation samplers. The Mercury Deposition Network programs include the (4) system blank program and (5) an interlaboratory comparison program. The results indicate consistently low levels of sample contamination, generally strong analytical laboratory performance, and low overall variability in concentration data imparted by field equipment. The NADP operations moved from its 40-year home at the Illinois State Water Survey to the Wisconsin State Laboratory of Hygiene in June 2018. The PCQA programs were modified and (or) temporarily curtailed during the transition in 2018. Bias and variability of sample analysis results were evaluated for the two Central Analytical Laboratories, and ongoing monitoring will be helpful to differentiate true environmental signals from the effects of changing laboratory conditions and performance. Results of quality assurance sample analyses are provided to document that NADP data continue to be of sufficient quality for the analysis of spatial distributions and time trends for chemical constituents in wet deposition.

\section{Introduction}

The U.S. Geological Survey (USGS) Precipitation Chemistry Quality Assurance project (PCQA) ensures that the National Atmospheric Deposition Program (NADP) provides data users with long-term, known-quality atmospheric wetdeposition information. As of 2019, the project is administered by the USGS Observing Systems Division, Hydrologic
Networks Branch in Denver, Colorado. Quality assurance (QA) results obtained by PCQA and presented in this report allow investigators to account for inherent variability and bias in NADP data potentially introduced by sample collection, processing, and laboratory analysis. The QA results obtained by PCQA also allow investigators to identify and quantify true environmental signals.

\section{Purpose and Scope}

The NADP incorporated three wet-deposition monitoring networks in 2017-18: (1) the National Trends Network (NTN), (2) the Mercury Deposition Network (MDN), and (3) the Atmospheric Integrated Research Monitoring Network (AIRMoN). This report updates the independent assessment of NADP data quality using PCQA results obtained for calendar years and water years 2017-18 (study period) for the NTN and MDN. Results obtained in previous years are used for comparison.

The field audit program and the system blank program assessed the effects of onsite exposure, sample handling, and shipping on the chemistry of NTN and MDN samples, respectively. Two interlaboratory comparison programs assessed the bias and variability of chemical analysis data from the Central Analytical Laboratories (CAL) at Illinois State Water Survey (ISWS), Champaign, Illinois, during 2017 and at Wisconsin State Laboratory of Hygiene (WSLH), Madison, Wisconsin, during 2018 and the Mercury Analytical Laboratory (HAL) at Eurofins Frontier Global Sciences, Inc., Bothell, Washington. The variability of NTN results was assessed using the colocated sampler program during water years 2017-18. Detailed information on USGS QA procedures and analytical methods for the NTN and MDN is available in Latysh and Wetherbee $(2005,2007)$ and Wetherbee and Martin (2016a).

Most of the PCQA programs are operated on a calendaryear basis, but the colocated sampler program is operated on a water-year basis. Each water year extends from October 1 through September 30 of the following year and is designated by the calendar year in which it ends. Monitoring sites for the colocated sampler program consist of two precipitation-sample collectors and a continuously recording precipitation gage. 
During water years $2017-18$, the colocated sampler program assessed the variability in NADP data obtained from N-CON collectors at the $\mathrm{CO} 11$ and $11 \mathrm{CO}$ sites colocated at the Arvada Community Gardens, Arvada, Colorado.

\section{Statistical Methods}

In this report, nonparametric, rank-based statistical methods are used in place of traditional statistics and hypothesis testing. The sign test (Kanji, 2006) was used to evaluate whether the median of differences between two groups is significantly different from zero. Network maximum contamination levels were evaluated at the 90 -percent significance level (alpha $[\alpha]=0.10$ ). Other statistical tests were evaluated at the 95-percent significance level $(\alpha=0.05)$, unless otherwise noted. Statistical analysis was performed using SAS version 9.4 software (SAS Institute Inc., 2016) and R version 3.5.2 (R Development Core Team, 2018).

Bias was quantified using relative and absolute differences and percent differences (Wetherbee and others, 2010). These parameters are calculated for each program, as follows:

Relative difference $=\mathrm{Cn}-\mathrm{Cc}$,

Absolute difference $=|\mathrm{Cn}-\mathrm{Cc}|$,

Relative percentage difference (RPD) $=[(\mathrm{Cn}-\mathrm{Cc}) / \mathrm{Ct}] \times 100$, and

Absolute percentage difference (APD) $=|(\mathrm{Cn}-\mathrm{Cc}) / \mathrm{Ct}| \times 100$

where

$\mathrm{Cn}$ is the sample concentration, in milligrams per liter or nanograms per liter, for the test sample, or precipitation depth in centimeters;

$\mathrm{Cc}$ is the sample concentration, in milligrams per liter or nanograms per liter, for the control sample or precipitation depth in centimeters; and

$\mathrm{Ct}$ is either Cc (field audit and system blank programs), a most probable target value (interlaboratory comparison programs), or the mean of $\mathrm{Cn}$ and $\mathrm{Cc}$ for replicate measurements using identical precipitation gages (colocated sampler program).

Variability was quantified in this report using $f$-pseudosigma ( $f$-psig), a nonparametric analog of the standard deviation of a statistical sample (Hoaglin and others, 1983):

$$
f \text {-pseudosigma }=\frac{75 \text { th percentile }-25 \text { th percentile }}{1.349}
$$

The $f$-pseudosigma ratio ( $f$-psig ratio) was also used to compare the variability of an entire dataset with the variability of a subset:

$$
f-\text { psig ratio }=\left(\frac{f p s i g_{\text {subset }}}{f p s i g_{o}}\right)
$$

where
fpsig subset
fpsigo

is the $f$-pseudosigma of the subset and is the overall $f$-pseudosigma of the entire dataset.

An $f$-psig ratio less than 1 indicates less variability in the subset than in the entire dataset, and an $f$-psig ratio greater than 1 indicates more variability in the subset than in the entire dataset.

Maximum contamination levels and precipitation-sample stability were determined by a calculation of upper confidence limits (UCL) on percentiles of concentration data using a binomial distribution (Hahn and Meeker, 1991). Their book describes a method for determining a distribution-free UCL for a percentile, which is appropriate for skewed data. This method uses order statistics, which are based on ranking the data from lowest to highest and applying binomial probability to determine the UCL. More detail is provided in Wetherbee and Martin (2016b).

Before determining contamination levels, concentrations less than the method detection limit (MDL) were changed to one-half the MDL. Helsel (2012) shows how such substitution leads to bias in hypothesis tests and calculation of statistical locations, but for this report, the substitution of one-half the detection limit had a minor effect on calculated percentiles because the percentage of censored values was typically less than 25 percent and was seen to have no discernable effect on quantification of the medians and interquartile ranges. Therefore, one-half the MDL was a convenient substitution for purposes of capturing reasonable estimates of bias and variability using the nonparametric methods described by Gibbons and Coleman (2001) for the Field Audit and System Blank data.

For the interlaboratory comparison program data, most probable values (MPVs) for concentrations of solutes in split samples of natural and synthetic rainwater solutions were calculated as the median concentrations for each analyte in each unique solution. The MPVs were calculated using the Not Above Detection Analysis (NADA) package in R to incorporate values below analytical detection limits. The NADA 
package uses survival-analysis techniques, such as the KaplanMeier method, to properly include censored values reported as less than analytical detection limits. The Kaplan-Meier method uses the empirical distribution functions of the positively skewed datasets, which are flipped end-to-end to plot the probabilities of exceedance of the observations. The method calculates the survival function probability (S) of "surviving" to the next lowest uncensored concentration, given the number of data at or below that concentration. A complete explanation is provided by Helsel (2012).

Colocated precipitation collectors generated pairs of replicate measurements of the same parameters at the same time and place to assess the overall variability of NADP results. The variability estimates are useful for verification of trends in NADP data. More detailed descriptions can be found in Wetherbee and others (2005a, 2006, 2009, 2010).

Data used to support the conclusions presented in this report are publicly available through two USGS data releases (Wetherbee, 2019, 2020).

\section{National Trends Network Quality Assurance Programs}

\section{Field Audit Program}

The field audit program uses equipment-rinse samples (bucket samples) paired with corresponding deionized water or synthetic precipitation solutions (bottle samples) to identify changes to chemical concentrations in NTN wet-deposition samples resulting from field exposure of the sample-collection apparatus (Latysh and Wetherbee, 2005; Wetherbee and others, 2010; Wetherbee and Martin, 2016a). After a week without wet deposition, site operators pour 75 percent of the volume of their field audit solution into the sample bucket and seal the bucket with a lid for 24 hours prior to decanting the solution to a clean sample bottle (bucket sample). The 25 percent of the field audit sample volume that remains in the sample bottle (bottle sample) never contacts any field sampling materials.

Contamination can be introduced to NADP samples by dissolution of materials residing on the bucket walls. In contrast, loss of dissolved constituents from the solution is possible through adsorption into the bucket walls. Dissolved constituents from the solution can also be lost through other chemical or biological processes. Contamination and sample stability are evaluated for network data by statistical analysis of paired "bucket-minus-bottle" concentration differences for field audit samples.

An NADP site operator who either processed and submitted a field audit sample to CAL or notified the USGS that an attempt was made to process the field audit sample during the year was considered to have participated in the field audit program. Field audit samples were shipped to 100 different sites in 2017. Shipment of field audit program samples was suspended in 2018 due to the transition of NADP operations from the ISWS to the WSLH. During 2017, 67 sites processed samples. During 2018, 9 sites processed samples that they received in 2016 or 2017. Data for a total of 76 complete pairs of field-audit samples were received from the CAL for the study period.

\section{Network Maximum Contamination Levels}

Using the binomial probability distribution function in SAS (SAS Institute, Inc., 2016) maximum concentrations of contaminants in NTN samples, with statistical confidence, were estimated using the 90-, 95-, and 99-percent UCLs for selected percentiles of the field audit, bucket-minus-bottle paired differences. As an example of the cumulative distributions for the UCLs, the 2016-18 results for sodium contamination concentrations are shown in figure 1 . The 90 -percent UCLs for the 90th percentiles of field-audit-paired concentration differences are calculated for each analyte, and these values are considered the network maximum contamination levels (NMCLs). The NMCLs serve as practical lower limits of quantitation for network-measured wet-deposition of chemical constituents (Wetherbee and others, 2010, 2013). The NMCLs are calculated for 3-year moving periods of time, but only 9 samples were processed and analyzed in 2018 (table 1).

The NMCL can be defined in three ways: (1) the NMCL is the maximum contamination expected in 90 percent of the samples with 90-percent confidence, (2) there is a 10-percent chance that contamination in NTN samples has been underestimated at the NMCL, or (3) there is 90-percent confidence that the contamination would exceed the NMCL in 10 percent of the NTN samples.

The 25th and 75th percentile values for all 2016-18 NTN monitoring data (Robert Larson, NADP Program Office, Wisconsin State Laboratory of Hygiene, written commun., 2019) are compared to estimated annual NMCLs in table 1. Trends in the NMCLs are illustrated for each analyte in figure 2. The NMCLs for calcium, magnesium, sodium, ammonium, and chloride have not changed appreciably since 2014, whereas the NMCL for potassium decreased approximately $\_0.003 \mathrm{mg} / \mathrm{L}$ during $2015-18$. The NMCLs for nitrate and sulfate increased by approximately $0.01 \mathrm{mg} / \mathrm{L}(2015-17)$ and then decreased again (2016-18) to levels lower than those measured during 2014-2016. These varying levels of sample contamination are small in terms of their absolute concentrations. However, the 2016-18 NMCLs for calcium, magnesium, sodium, and potassium were equivalent to the 22nd, 26th, 20th, and 13th percentile concentrations, respectively, in NADP samples during the same period. Any NTN concentrations lower than the NMCLs cannot be differentiated from contamination. In other words, the lower 22 percent of all NTN calcium concentrations cannot be differentiated from contamination, and so on. The ammonium NMCL $(0.030 \mathrm{mg} / \mathrm{L})$ was at the 14 th percentile of NTN data values. The NMCLs for chloride $(0.022 \mathrm{mg} / \mathrm{L})$, nitrate $(0.071 \mathrm{mg} / \mathrm{L})$, 
Table 1. National Atmospheric Deposition Program's National Trends Network method detection limits, network maximum contamination levels, and analyte losses estimated from field audit samples in addition to calculated concentration quartiles for all valid monitoring data, 2015-18.

[NTN, National Trends Network; MDL, method detection limit; NMCL, network maximum contamination level; NADP NTN, National Atmospheric Deposition Program National Trends Network; Q1, 25th percentile; Q3, 75th percentile; all units in milligrams per liter except hydrogen ion (microequivalents per liter); n.d., no data; $\mathrm{p}>|\mathrm{M}|]$, sign test $p$-value, probability of rejecting the null hypothesis: "The true median of the differences between laboratory results and the most probable value is zero," when true]

\begin{tabular}{|c|c|c|c|c|c|c|c|c|c|c|}
\hline \multirow{2}{*}{ Analyte } & \multicolumn{2}{|c|}{$\begin{array}{l}\text { NTN Method } \\
\text { detection limits } \\
\text { (MDL) }\end{array}$} & \multirow{2}{*}{$\begin{array}{c}\text { Estimated } \\
\text { network max- } \\
\text { imum con- } \\
\text { tamination } \\
\text { level (NMCL)2 } \\
\text { 2015-17 }\end{array}$} & \multirow{2}{*}{$\begin{array}{l}\text { Estimated net- } \\
\text { work maximum } \\
\text { contamination } \\
\text { level (NMCL)1, } \\
2016-18\end{array}$} & \multirow{2}{*}{$\begin{array}{c}\text { Median } \\
\text { concentration } \\
\text { difference } \\
\text { (units) } \\
\text { 2016-18 }\end{array}$} & \multirow{2}{*}{$\begin{array}{c}\text { Sign test } \\
p>|M| \\
2016-18\end{array}$} & \multirow{2}{*}{$\begin{array}{c}\text { Maximum } \\
\text { analyte } \\
\text { loss }^{3} \\
2016-18\end{array}$} & \multicolumn{3}{|c|}{$\begin{array}{l}\text { Valid 2016-18 NADP NTN } \\
\text { data quartile values }{ }^{4}\end{array}$} \\
\hline & 2017 & 12018 & & & & & & 01 & Median & 03 \\
\hline Calcium & 0.002 & 0.011 & 0.041 & 0.042 & 0.005 & $<0.001$ & 0.004 & 0.048 & 0.109 & 0.252 \\
\hline Magnesium & 0.001 & 0.003 & 0.009 & 0.011 & 0.001 & $<0.001$ & 0.002 & 0.010 & 0.023 & 0.048 \\
\hline Sodium & 0.001 & 0.005 & 0.015 & 0.015 & 0.001 & $<0.001$ & 0.005 & 0.019 & 0.051 & 0.151 \\
\hline Potassium & 0.001 & 0.005 & 0.007 & 0.007 & 0.000 & $<0.001$ & 0.001 & 0.011 & 0.021 & 0.041 \\
\hline Ammonium & 0.008 & 0.009 & 0.030 & 0.030 & 0.004 & 0.072 & 0.020 & 0.113 & 0.256 & 0.514 \\
\hline Chloride & 0.003 & 0.006 & 0.024 & 0.022 & 0.002 & $<0.001$ & 0.006 & 0.041 & 0.089 & 0.250 \\
\hline Nitrate & 0.005 & 0.008 & 0.095 & 0.071 & 0.003 & $<0.001$ & 0.007 & 0.360 & 0.653 & 1.098 \\
\hline Sulfate & 0.005 & 0.007 & 0.067 & 0.054 & 0.002 & $<0.001$ & 0.013 & 0.226 & 0.411 & 0.694 \\
\hline Hydrogen ion & n.d. & n.d. & 1.25 & 1.11 & -0.320 & $<0.001$ & 2.50 & 1.148 & 3.891 & 7.244 \\
\hline
\end{tabular}

${ }^{1}$ Higher of the two MDLs reported by each Central Analytical Laboratory in 2018.

${ }^{2}$ Calculated as the 90-percent upper confidence limits for the 90th percentiles of 2016-18 field audit paired differences using the binomial distribution function in SAS (SAS Institute, Inc., 2001), where differences are calculated as bucket-minus-bottle.

${ }^{3}$ Calculated as the 90-percent upper confidence limits for the 90th percentiles of 2016-18 field audit paired differences using the binomial distribution function in SAS (SAS Institute, Inc., 2001), where differences are calculated as bottle-minus-bucket.

4Data for all valid 2016-18 NTN samples obtained from Robert Larson (Wisconsin State Laboratory of Hygiene, University of Wisconsin, written commun., 2019).

and sulfate $(0.054 \mathrm{mg} / \mathrm{L})$, were at the 9 th, $2 \mathrm{nd}$, and 2 nd NTN concentration percentiles, respectively. Therefore, contamination for anions is lower than for cations.

\section{Analyte Losses}

Maximum values for analyte losses were the same for the 2015-17 and 2016-18 periods (fig. $3 A$ and $3 B$ ). Nitrate loss was similar to the 2017-18 MDLs, which indicates that nitrate losses from NTN samples were small (table 1). Ammonium loss increased from $0.010 \mathrm{mg} / \mathrm{L}$ (2014-2016) to $0.020 \mathrm{mg} / \mathrm{L}$ (2015-2017), which is approximately 2.2 times the $2018 \mathrm{MDL}$ for ammonium $(0.009 \mathrm{mg} / \mathrm{L})$. Hydrogen ion maximum loss was 2.50 microequivalents per liter $(\mu \mathrm{eq} / \mathrm{L})$, which has not changed since 2014 . These values are considered to represent the maximum expected losses of ammonium, nitrate, and hydrogen ion from NTN samples with 90 percent confidence.

\section{National Trends Network Interlaboratory Comparison Program}

The standing objectives of the NTN interlaboratory comparison program are to (1) estimate the variability and bias in data reported by CAL and other participating laboratories and (2) facilitate integration of data from various wet-deposition monitoring networks without any attempt to account for the different onsite protocols used by different monitoring networks. Eleven laboratories participated in the interlaboratory comparison program during 2017-18: (1) Asia Center for Air Pollution Research (ACAP) in Niigata-shi, Japan; (2) NADP CAL, Illinois State Water Survey, in Champaign, Ill., (ICAL); (3) AMEC Foster Wheeler, Inc. (AMEC), renamed Wood Group, Inc. (WOOD), in Gainesville, Florida; (4) Ontario Ministry of Environment and Climate Change-Dorset Chemistry Laboratory (MOECC), in Dorset, Ontario, Canada; (5) Environment and Climate Change Canada, Science and Technology Branch (ECST) in Downsview, Ontario, Canada; (6) Norwegian Institute for Air Research (NILU) in Kjeller, Norway; (7) Carey Institute of Ecosystem Studies (CIES), in Millbrook, New York; (8) U.S. Department of Agriculture 


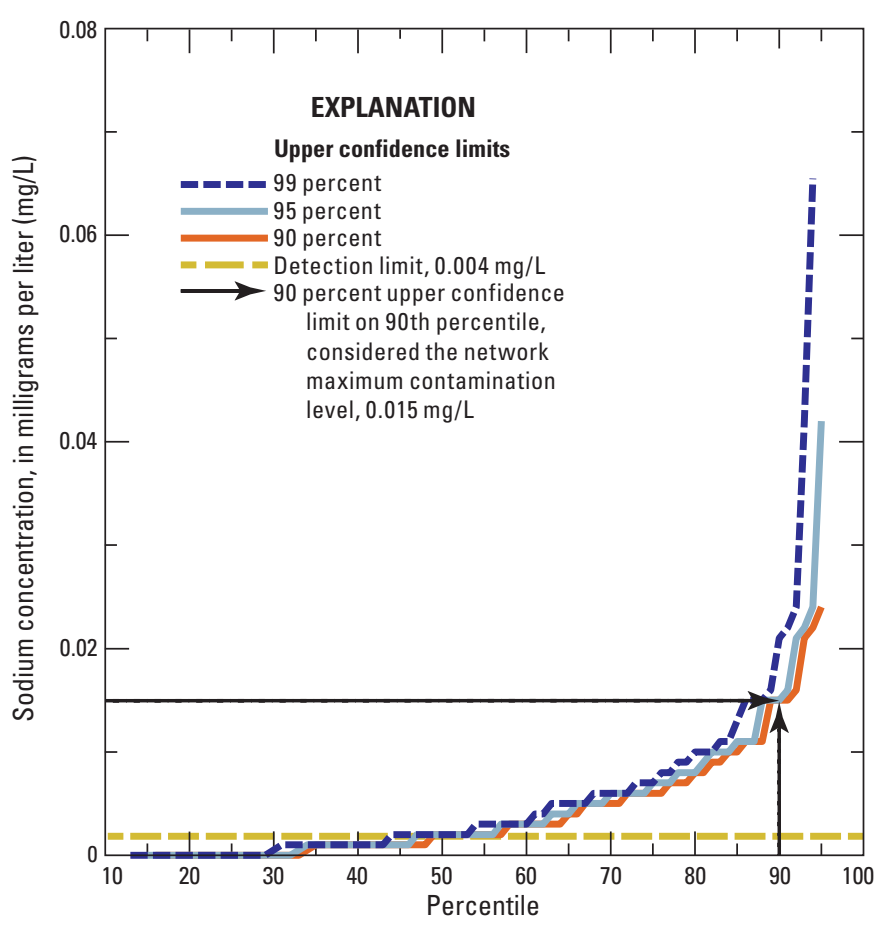

Figure 1. Distributions of upper confidence limits for sodium contamination concentrations measured by the field audit program, 2016-18.
Forest Service, Northern Research Station (NRS), in Durham, New Hampshire; (9) RTI International (RTI), in Research Triangle Park, North Carolina, (10) Universidad Nacional Autonoma de Mexico (UNAM), Centro de Ciencias de la Atmosfera, in Mexico City, Mexico; and (11) NADP CAL, Wisconsin State Laboratory of Hygiene, in Madison, Wisc. (WCAL). The WCAL began participation in October 2017.

Each of the participating laboratories received four samples from PCQA every month for chemical analysis. The three types of samples used in the interlaboratory comparison program included (1) synthetic standard reference samples prepared by PCQA, which are traceable to National Institute of Standards and Technology (NIST) reference materials (NIST-traceable materials); (2) de-ionized water blank samples prepared by PCQA; and (3) natural wet-deposition samples collected at NTN sites, blended by CAL, and sent to PCQA for shipping to the laboratories as blind samples (Wetherbee and Martin, 2016a). Synthetic precipitation samples used in the interlaboratory comparison program were made from stock solutions prepared by High Purity Standards, Charleston, South Carolina. Natural samples were filtered through 0.45-micrometer filters; bottled in 60-, 125-, and 250-milliliter polyethylene bottles by CAL; and shipped in chilled, insulated containers to the PCQA to enhance stability of nutrient

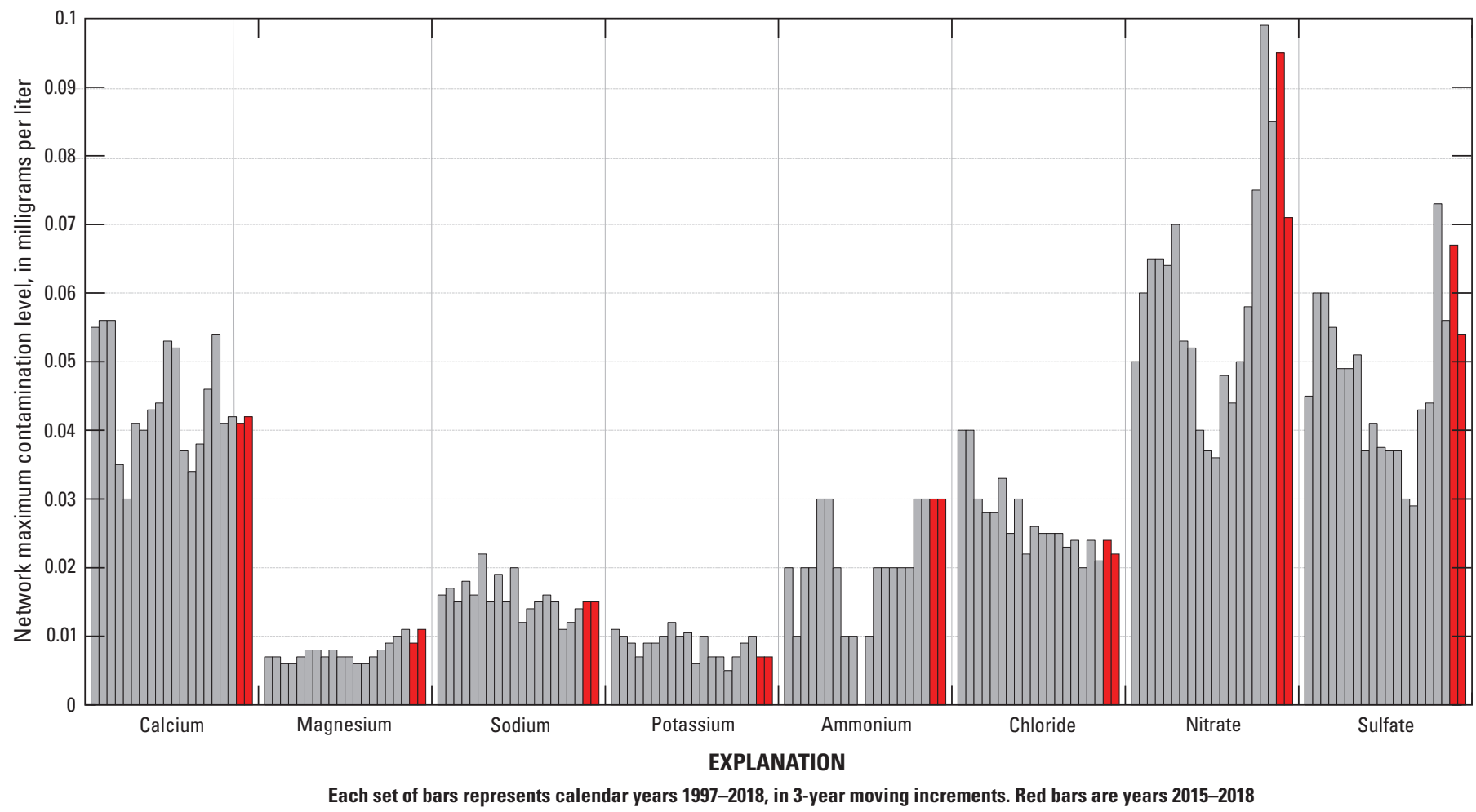

Figure 2. Network maximum contamination levels for National Trends Network analytes calculated using 3-year moving increments, 1997-2018. 

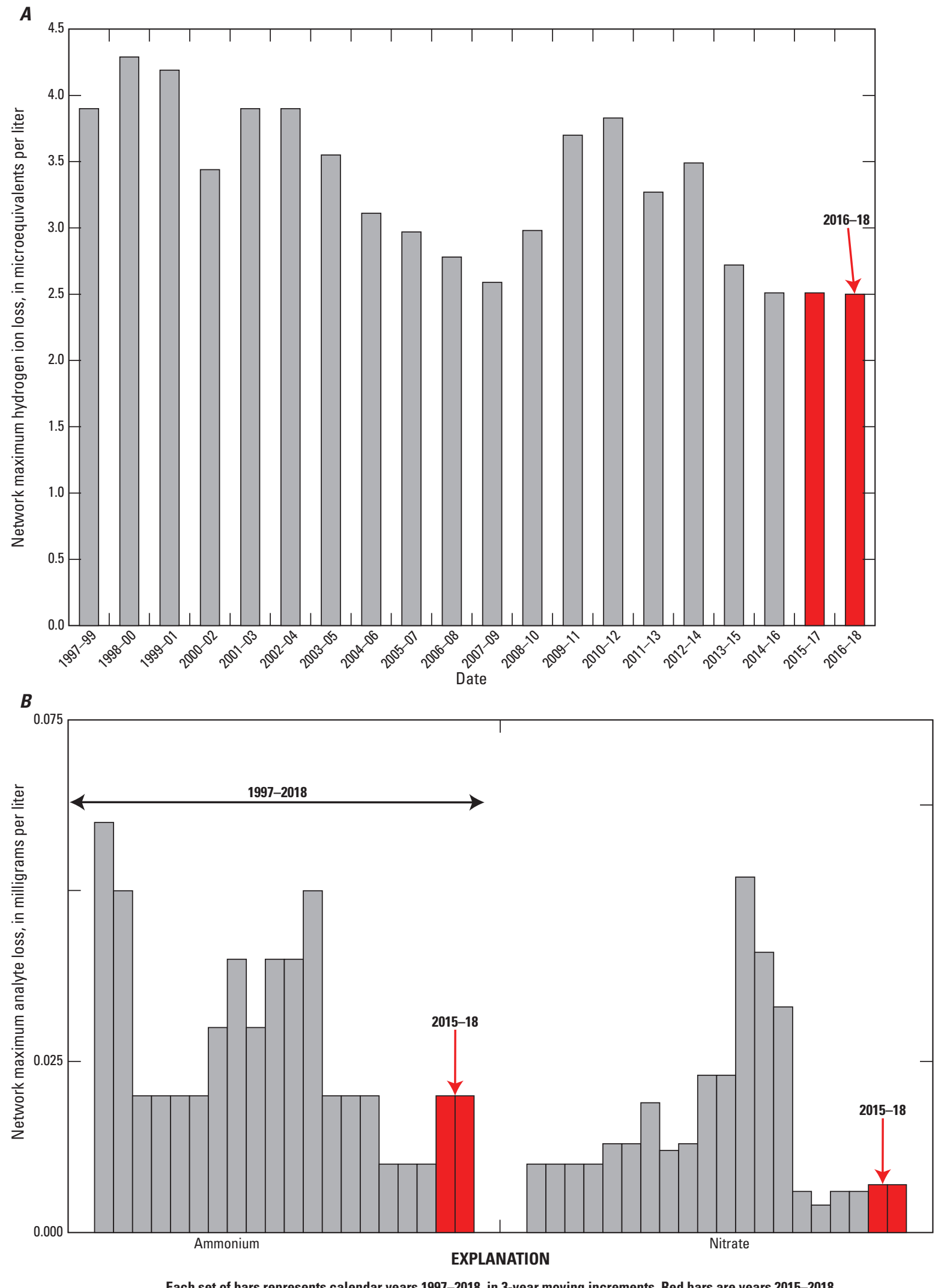

Figure 3. Maximum loss of $A$, hydrogen ion and $B$, ammonium and nitrate from weekly National Trends Network samples calculated using 3-year moving increments, 1997-2018. 
analytes - ammonium, nitrate, and sulfate - in the samples (Tchobanoglous and Schroeder, 1987; U.S. Geological Survey, 2002).

Median concentrations of calcium, magnesium, sodium, potassium, ammonium, chloride, nitrate, sulfate, bromide, and hydrogen ion and median specific conductance were computed by solution from the data submitted by all participating laboratories. The median values were considered to be equal to the most probable values (MPVs). Censored concentration values reported as less than the MDL were included in the estimation of MPVs for each solution using the Kaplan Meier method (Helsel, 2012). The largest percentages of censored concentration values observed for this program during 2017-18 were for magnesium and potassium, most commonly with natural wet-deposition samples.

The MPVs for the synthetic precipitation solutions and the number of samples analyzed per solution are listed in table 2 by solution identifier: SP2B, SP21B, SP22B. Data from each laboratory were compared against these MPVs to evaluate bias. Only ICAL, NRS, CIES, and WCAL analyzed the samples for bromide. The RTI laboratory routinely analyzed the samples only for chloride, nitrate, and sulfate plus 16 samples for sodium, potassium, and ammonium in 2018. The ECST, NRS, and RTI laboratories did not analyze the samples for specific conductance. The NRS and RTI laboratories did not measure $\mathrm{pH}$ for any of the samples. Data are missing for: AMEC in December 2017, ECST in September 2018, MOECC in November 2018, NRS in December of 2017 and 2018, and UNAM in November and December 2018 due to shipping problems.

\section{Interlaboratory Comparison Program Bias and Variability}

Interlaboratory bias for the participating laboratories was evaluated using the following methods: (1) comparison of the medians of the differences between laboratory results and MPVs, (2) hypothesis testing using the sign test, and (3) comparison of laboratory results for de-ionized water samples. The arithmetic signs of the median differences indicate whether the reported results for each constituent are positively or negatively biased. The sign test null hypothesis is the true median of the reported-minus-MPV differences is zero. Test results were evaluated at the $\alpha=0.05$ significance level for a two-tailed test.

Calculated variation between laboratories was compared using the $f$-psig ratios (eq. 6). Analytical detection limits are reported for each laboratory in table 3. Results for variability and bias within the analytical data reported by each of the participating laboratories are presented in tables 4 and 5 . Shaded values in tables 4 and 5 identify analytes for which bias was found to be both statistically $(\alpha=0.05)$ and practically significant. For this program, statistically significant bias was determined to be of practical significance only when the absolute value of the median relative concentration difference was greater than the participating laboratory's analytical method detection limit (table 3).

During 2017, significant bias above the detection limits was observed for ICAL (calcium, potassium, and ammonium), MOECC (nitrate), ECST (sodium), NILU (nitrate), NRS (sodium, chloride, and bromide), CIES (calcium, sodium, potassium, nitrate, and sulfate), RTI (nitrate), WCAL (chloride), and UNAM (nitrate and sulfate) (table 4). During 2018, significant bias above the method detection limits was identified for ACAP (sodium), ICAL (calcium and potassium), MOECC (nitrate), ECST (sodium), NILU (nitrate), NRS (sodium, chloride, and bromide), CIES (calcium, sodium, bromide, and nitrate), RTI (ammonium), WCAL (chloride), and UNAM (nitrate and sulfate) (table 5). The ECST, ICAL, AMEC/WOOD, RTI, and WCAL laboratories had comparable, low overall variability among the participating laboratories during $2017-18$ as indicated by most $f$-psig ratios less than 1.00 (tables 4 and 5).

Four de-ionized water blank samples were analyzed annually by each laboratory. A summary of results for the blanks is shown in table 6 . No results were reported above analytical detection limits for blank samples for the ECST, NILU, RTI, UNAM, and AMEC/WOOD laboratories during 2017-18. The ACAP laboratory reported detections for all constituents in 2018 for at least two blanks per analyte. The ICAL reported detections for potassium and ammonium in 2 blanks in 2017 and for calcium (1), magnesium (1), potassium (2), ammonium (1), and chloride (1) in 2018. The ECST laboratory reported no detections of analytes in blanks for 2017 and detections for calcium (1), sodium (1), and potassium (2) in 2018. The MOECC laboratory reported detections in blanks for calcium (4), potassium (2), ammonium (5), chloride (2), nitrate (3), and sulfate (2) during 2017-18. The NRS laboratory reported detections in blanks for calcium (2), magnesium (1), sodium (1), potassium (4), ammonium (1), chloride (2), nitrate (3), and sulfate (2) for 2017-18 combined. The WCAL reported a detection for magnesium in a blank during 2018 and analyzed no blanks in 2017.

\section{Interlaboratory Comparison Program Control Charts}

Each participating laboratory's results were compared to the MPVs over time in control charts. Analyte determinations that exceeded the control limits ( $\pm 3 f$-psig) during 2017-18 are summarized in table 7 . Each laboratory was provided with its own sets of control charts.

Control charts for ICAL and WCAL for 2017-18 are compared in figures $4 A, 4 B$, and $4 C$. Points in the control charts are color- and symbol-coded by solution type to provide a visual indication of potential solution-specific bias. A potential positive bias is observed for the SP2B solution, indicated by the green diamond symbols in figures $4 A, 4 B$, and $4 C$. Control charts for base cation results are shown in figure $4 A$. 

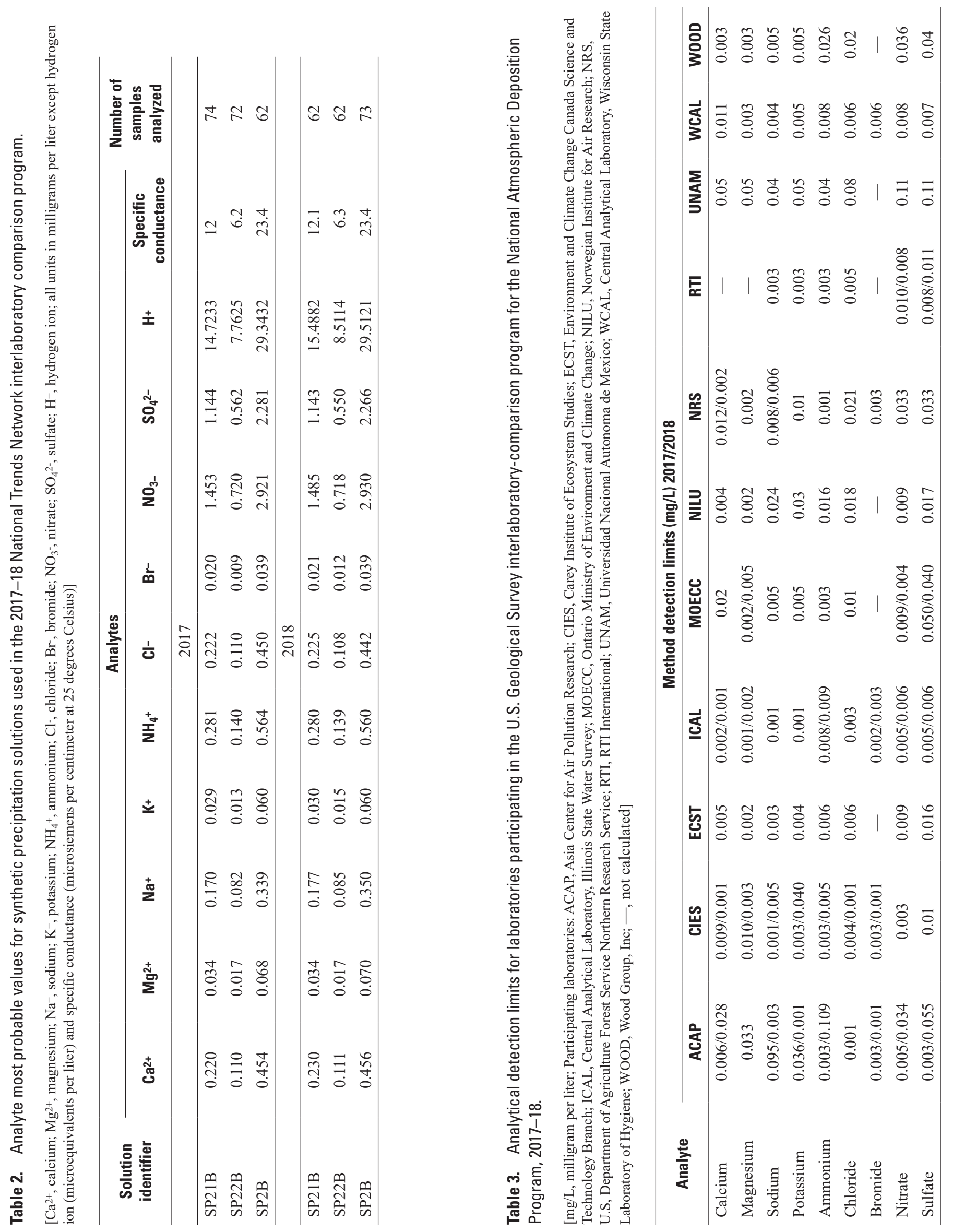
Table 4. Median differences between reported constituent concentrations and most probable values for synthetic wet-deposition samples, 2017 interlaboratory comparison program.

[ACAP, Asia Center for Air Pollution Research; ICAL, Central Analytical Laboratory, Illinois State Water Survey; AMEC/WOOD, AMEC Foster-Wheeler/ Wood Group; MOECC, Ontario Ministry of Environment and Climate Change; ECST, Environment and Climate Change Canada Science and Technology Branch; NILU, Norwegian Institute for Air Research; NRS, U.S. Forest Service Northern Research Station; CIES, Carey Institute of Ecosystem Studies; RTI, RTI International; WCAL, Central Analytical Laboratory, Wisconsin State Laboratory of Hygiene; UNAM, Universidad Nacional Autonoma de Mexico; all units in milligrams per liter, except hydrogen ion (microequivalents per liter) and specific conductance (microsiemens per centimeter at 25 degrees Celsius); overall $f$-psig, $f$-pseudosigma for all participating laboratories; median diff., median of differences between each laboratory's individual results and the most probable value during 2017; $f$-psig ratio, ratio of each individual laboratory's $f$-pseudosigma to the overall $f$-pseudosigma; sign test $p$-value, probability of rejecting the null hypothesis: "The true median of the differences between laboratory results and the most probable value is zero," when true; values are shaded where median bias is greater than the method detection limit (table 3 ) and statistically significant $(\alpha=0.05)$ (Kanji, 2006); Spec. cond, specific conductance; - , not calculated; $<$, less than]

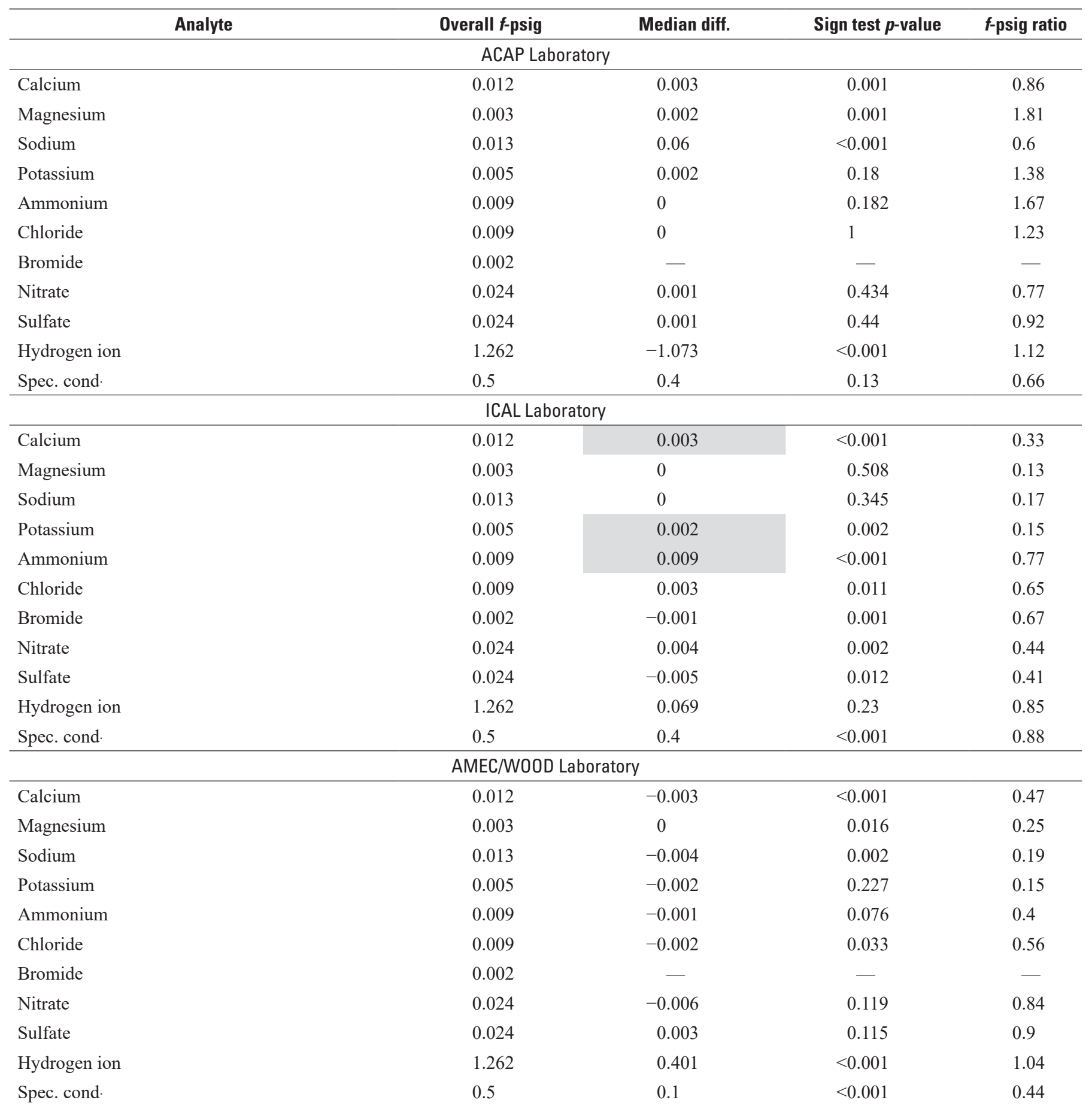


Table 4. Median differences between reported constituent concentrations and most probable values for synthetic wet-deposition samples, 2017 interlaboratory comparison program.-Continued

[ACAP, Asia Center for Air Pollution Research; ICAL, Central Analytical Laboratory, Illinois State Water Survey; AMEC/WOOD, AMEC Foster-Wheeler/ Wood Group; MOECC, Ontario Ministry of Environment and Climate Change; ECST, Environment and Climate Change Canada Science and Technology Branch; NILU, Norwegian Institute for Air Research; NRS, U.S. Forest Service Northern Research Station; CIES, Carey Institute of Ecosystem Studies; RTI, RTI International; WCAL, Central Analytical Laboratory, Wisconsin State Laboratory of Hygiene; UNAM, Universidad Nacional Autonoma de Mexico; all units in milligrams per liter, except hydrogen ion (microequivalents per liter) and specific conductance (microsiemens per centimeter at 25 degrees Celsius); overall $f$-psig, $f$-pseudosigma for all participating laboratories; median diff., median of differences between each laboratory's individual results and the most probable value during 2017 ; $f$-psig ratio, ratio of each individual laboratory's $f$-pseudosigma to the overall $f$-pseudosigma; sign test $p$-value, probability of rejecting the null hypothesis: "The true median of the differences between laboratory results and the most probable value is zero," when true; values are shaded where median bias is greater than the method detection limit (table 3 ) and statistically significant $(\alpha=0.05)$ (Kanji, 2006); Spec. cond, specific conductance; - , not calculated; <, less than]

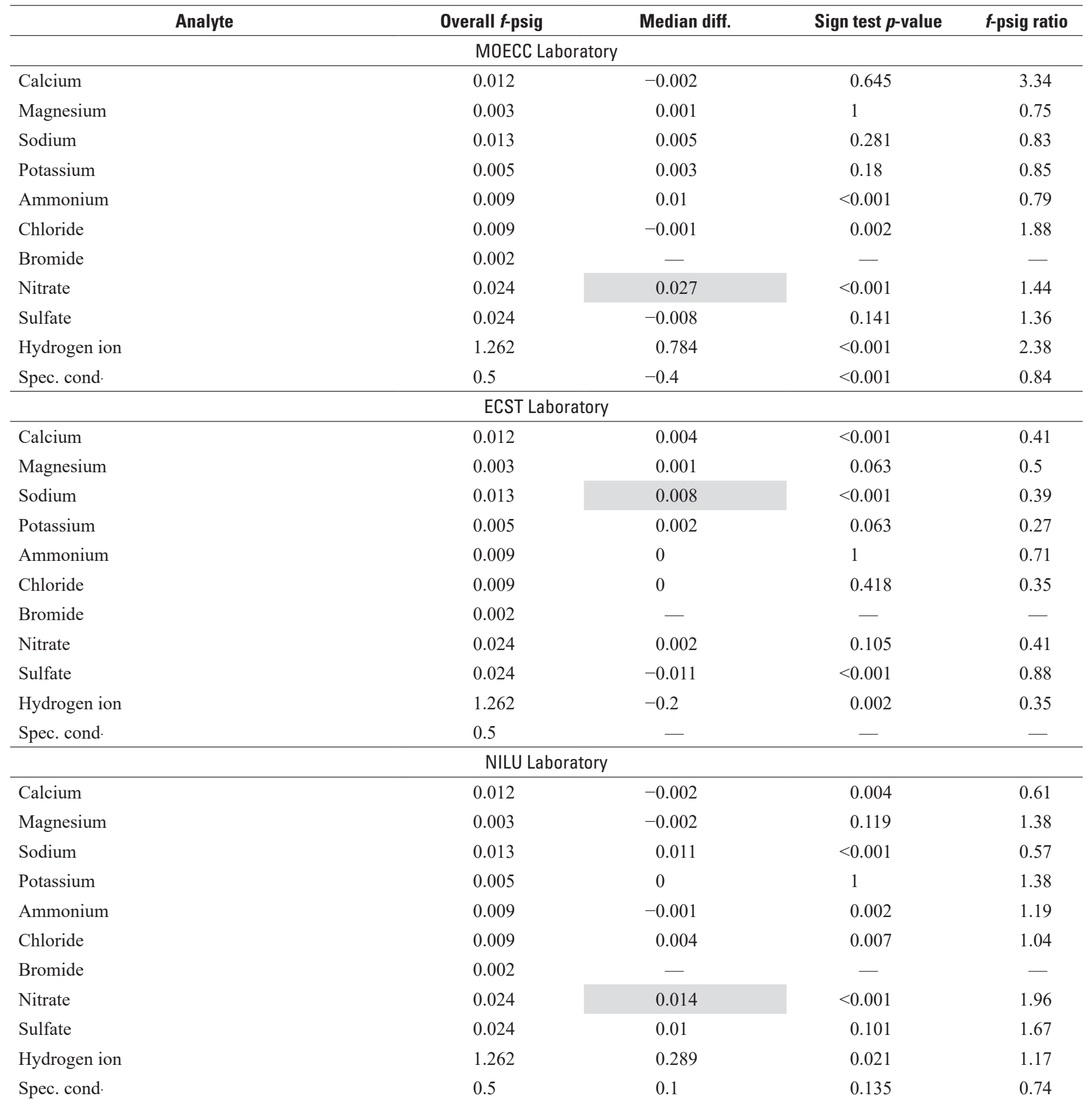


Table 4. Median differences between reported constituent concentrations and most probable values for synthetic wet-deposition samples, 2017 interlaboratory comparison program.-Continued

[ACAP, Asia Center for Air Pollution Research; ICAL, Central Analytical Laboratory, Illinois State Water Survey; AMEC/WOOD, AMEC Foster-Wheeler/ Wood Group; MOECC, Ontario Ministry of Environment and Climate Change; ECST, Environment and Climate Change Canada Science and Technology Branch; NILU, Norwegian Institute for Air Research; NRS, U.S. Forest Service Northern Research Station; CIES, Carey Institute of Ecosystem Studies; RTI, RTI International; WCAL, Central Analytical Laboratory, Wisconsin State Laboratory of Hygiene; UNAM, Universidad Nacional Autonoma de Mexico; all units in milligrams per liter, except hydrogen ion (microequivalents per liter) and specific conductance (microsiemens per centimeter at 25 degrees Celsius); overall $f$-psig, $f$-pseudosigma for all participating laboratories; median diff., median of differences between each laboratory's individual results and the most probable value during 2017; $f$-psig ratio, ratio of each individual laboratory's $f$-pseudosigma to the overall $f$-pseudosigma; sign test $p$-value, probability of rejecting the null hypothesis: "The true median of the differences between laboratory results and the most probable value is zero," when true; values are shaded where median bias is greater than the method detection limit (table 3$)$ and statistically significant $(\alpha=0.05)$ (Kanji, 2006); Spec. cond, specific conductance; - , not calculated; $<$, less than]

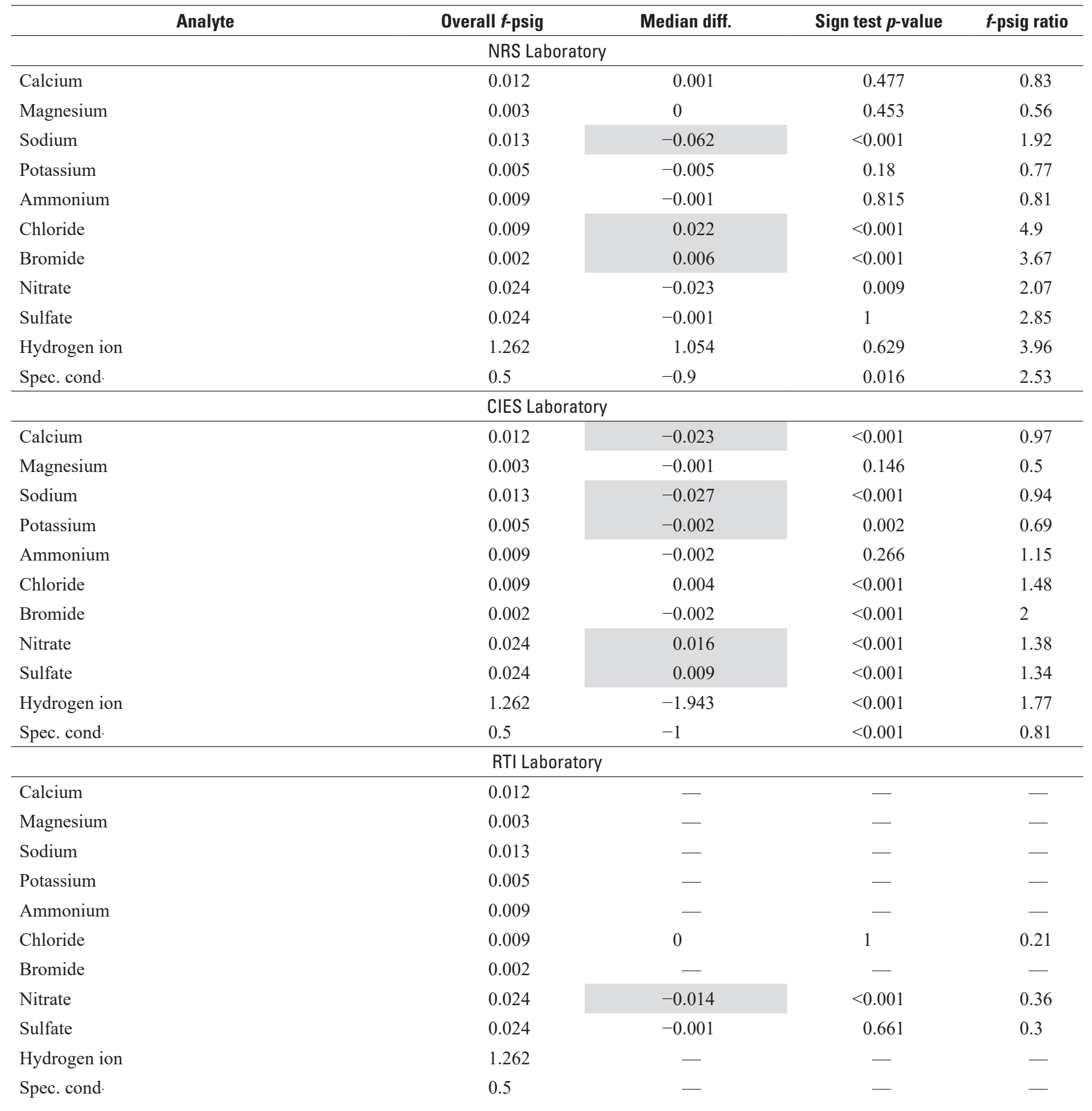


Table 4. Median differences between reported constituent concentrations and most probable values for synthetic wet-deposition samples, 2017 interlaboratory comparison program.-Continued

[ACAP, Asia Center for Air Pollution Research; ICAL, Central Analytical Laboratory, Illinois State Water Survey; AMEC/WOOD, AMEC Foster-Wheeler/ Wood Group; MOECC, Ontario Ministry of Environment and Climate Change; ECST, Environment and Climate Change Canada Science and Technology Branch; NILU, Norwegian Institute for Air Research; NRS, U.S. Forest Service Northern Research Station; CIES, Carey Institute of Ecosystem Studies; RTI, RTI International; WCAL, Central Analytical Laboratory, Wisconsin State Laboratory of Hygiene; UNAM, Universidad Nacional Autonoma de Mexico; all units in milligrams per liter, except hydrogen ion (microequivalents per liter) and specific conductance (microsiemens per centimeter at 25 degrees Celsius); overall $f$-psig, $f$-pseudosigma for all participating laboratories; median diff., median of differences between each laboratory's individual results and the most probable value during 2017 ; $f$-psig ratio, ratio of each individual laboratory's $f$-pseudosigma to the overall $f$-pseudosigma; sign test $p$-value, probability of rejecting the null hypothesis: "The true median of the differences between laboratory results and the most probable value is zero," when true; values are shaded where median bias is greater than the method detection limit (table 3) and statistically significant ( $\alpha=0.05)$ (Kanji, 2006); Spec. cond, specific conductance; - , not calculated; <, less than]

\begin{tabular}{|c|c|c|c|c|}
\hline Analyte & Overall $f$-psig & Median diff. & Sign test $p$-value & $f$-psig ratio \\
\hline \multicolumn{5}{|c|}{ WCAL Laboratory } \\
\hline Calcium & 0.012 & 0.003 & $<0.001$ & 0.84 \\
\hline Magnesium & 0.003 & 0 & 0.219 & 0.69 \\
\hline Sodium & 0.013 & 0 & 0.503 & 0.61 \\
\hline Potassium & 0.005 & -0.001 & 0.109 & 0.31 \\
\hline Ammonium & 0.009 & -0.001 & 0.144 & 0.17 \\
\hline Chloride & 0.009 & -0.008 & $<0.001$ & 0.81 \\
\hline Bromide & 0.002 & 0.003 & 0.078 & 1.17 \\
\hline Nitrate & 0.024 & -0.002 & 1 & 0.68 \\
\hline Sulfate & 0.024 & -0.004 & 0.058 & 0.34 \\
\hline Hydrogen ion & 1.262 & 1.326 & 0.001 & 3.06 \\
\hline Spec. cond. & 0.5 & -0.1 & 0.401 & 0.81 \\
\hline \multicolumn{5}{|c|}{ UNAM Laboratory } \\
\hline Calcium & 0.012 & -0.005 & 0.154 & 2.47 \\
\hline Magnesium & 0.003 & 0.006 & 0.004 & 4.63 \\
\hline Sodium & 0.013 & -0.002 & 0.442 & 1.83 \\
\hline Potassium & 0.005 & -0.002 & 1 & 2.46 \\
\hline Ammonium & 0.009 & -0.01 & 0.001 & 1.63 \\
\hline Chloride & 0.009 & -0.011 & $<0.001$ & 1.65 \\
\hline Bromide & 0.002 & - & - & - \\
\hline Nitrate & 0.024 & -0.024 & $<0.001$ & 1.02 \\
\hline Sulfate & 0.024 & 0.025 & $<0.001$ & 1.17 \\
\hline Hydrogen ion & 1.262 & 0.264 & 0.003 & 1.5 \\
\hline Spec. cond & 0.5 & -0.2 & 0.002 & 0.49 \\
\hline
\end{tabular}

The ICAL results indicate a slight positive bias for sodium and potassium in the latter half of 2018. The WCAL results indicate a slight negative bias for sodium in late 2018.

Control charts for ammonium, chloride, bromide, and nitrate are shown in figure $4 B$. No bias for ammonium results reported by ICAL and WCAL is evident. However, the WCAL control charts indicate a negative bias for chloride and a positive bias for bromide results through November 2018. In November 2018, the WCAL chloride results match the MPVs, and the bias for bromide results becomes negative. The WCAL nitrate results indicate a slight negative bias, except for solution SP2B, until July 2018 when the bias shifts positive with several analyses outside the statistical control limits. The ICAL nitrate results trend toward a positive bias at about the same time as the WCAL shift in bias for nitrate. Additionally, an ICAL result for solution SP21B was out of statistical control in November 2018. There were several laboratories that did not report data for November and December, and this may have adversely affected the MPVs for solutions analyzed in this time period.

The control charts in figure $4 C$ indicate a positive bias in WCAL sulfate results, primarily for solution SP2B, but the same bias for SP2B is not observed in the ICAL results. Hydrogen-ion concentrations calculated from $\mathrm{pH}$ 
Table 5. Median differences between reported constituent concentrations and most probable values for synthetic wet-deposition samples, 2018 interlaboratory comparison program.

[ACAP, Asia Center for Air Pollution Research; ICAL, Central Analytical Laboratory, Illinois State Water Survey; WOOD, Wood Group; MOECC, Ontario Ministry of Environment and Climate Change; ECST, Environment and Climate Change Canada Science and Technology Branch; NILU, Norwegian Institute for Air Research; NRS, U.S. Forest Service Northern Research Station; CIES, Carey Institute of Ecosystem Studies; RTI, RTI International; WCAL, Central Analytical Laboratory, Wisconsin State Laboratory of Hygiene; UNAM, Universidad Nacional Autonoma de Mexico; all units in milligrams per liter except hydrogen ion (microequivalents per liter) and specific conductance (microsiemens per centimeter at 25 degrees Celsius); overall $f$-psig, $f$-pseudosigma for all participating laboratories; median diff., median of differences between each laboratory's individual results and the most probable value during $2018 ; f$-psig ratio, ratio of each individual laboratory's $f$-pseudosigma to the overall $f$-pseudosigma; sign test $p$-value, probability of rejecting the null hypothesis: "The true median of the differences between laboratory results and the most probable value is zero," when true; values are shaded where median bias is greater than the method detection limit (table 3) and statistically significant $(\alpha=0.05)$ (Kanji, 2006); Spec. cond, specific conductance; —, not calculated; <, less than]

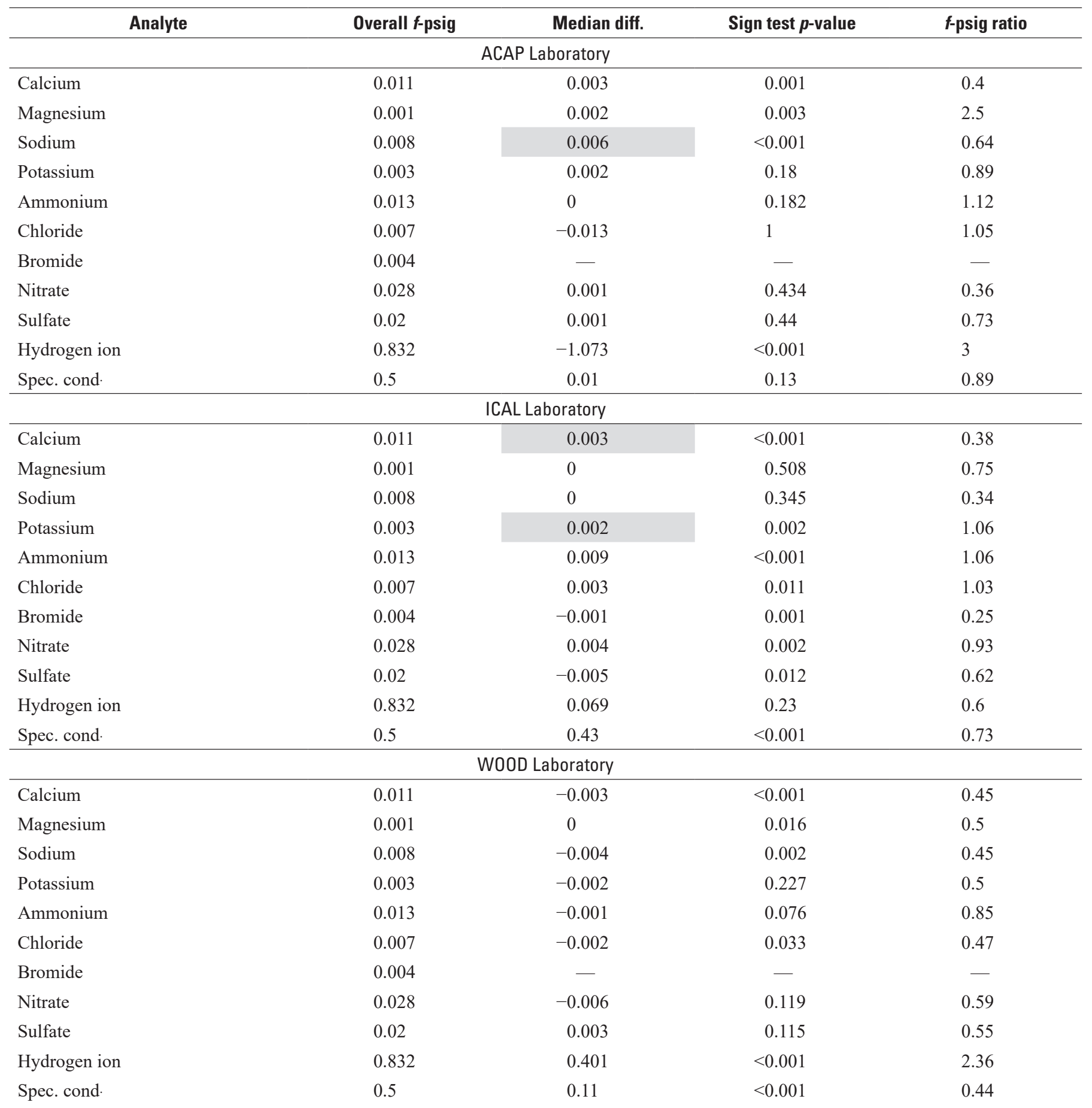


Table 5. Median differences between reported constituent concentrations and most probable values for synthetic wet-deposition samples, 2018 interlaboratory comparison program.-Continued

[ACAP, Asia Center for Air Pollution Research; ICAL, Central Analytical Laboratory, Illinois State Water Survey; WOOD, Wood Group; MOECC, Ontario Ministry of Environment and Climate Change; ECST, Environment and Climate Change Canada Science and Technology Branch; NILU, Norwegian Institute for Air Research; NRS, U.S. Forest Service Northern Research Station; CIES, Carey Institute of Ecosystem Studies; RTI, RTI International; WCAL, Central Analytical Laboratory, Wisconsin State Laboratory of Hygiene; UNAM, Universidad Nacional Autonoma de Mexico; all units in milligrams per liter except hydrogen ion (microequivalents per liter) and specific conductance (microsiemens per centimeter at 25 degrees Celsius); overall $f$-psig, $f$-pseudosigma for all participating laboratories; median diff., median of differences between each laboratory's individual results and the most probable value during 2018; $f$-psig ratio, ratio of each individual laboratory's $f$-pseudosigma to the overall $f$-pseudosigma; sign test $p$-value, probability of rejecting the null hypothesis: "The true median of the differences between laboratory results and the most probable value is zero," when true; values are shaded where median bias is greater than the method detection limit (table 3) and statistically significant ( $\alpha=0.05)$ (Kanji, 2006); Spec. cond, specific conductance; - , not calculated; $<$, less than]

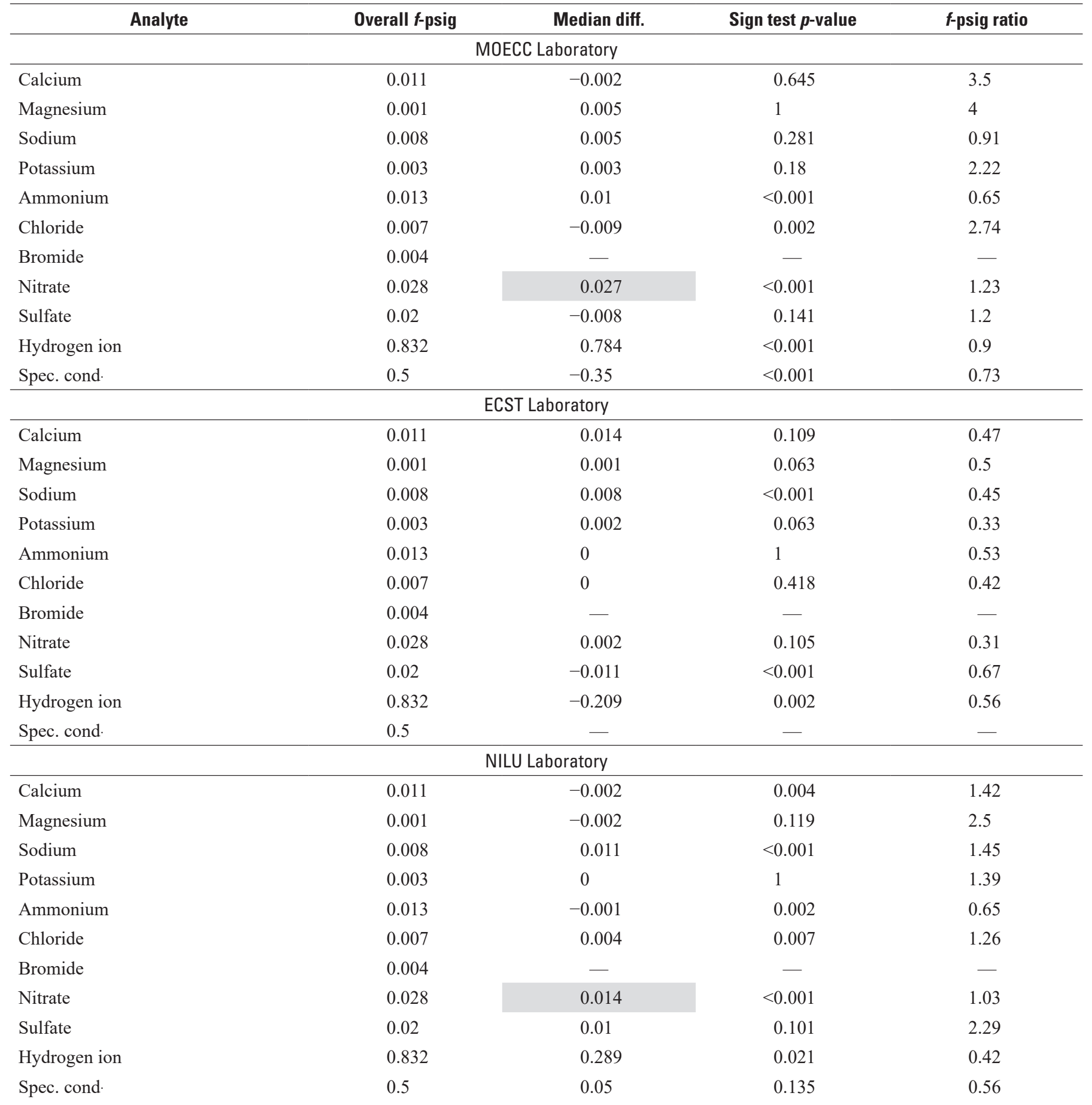


Table 5. Median differences between reported constituent concentrations and most probable values for synthetic wet-deposition samples, 2018 interlaboratory comparison program.-Continued

[ACAP, Asia Center for Air Pollution Research; ICAL, Central Analytical Laboratory, Illinois State Water Survey; WOOD, Wood Group; MOECC, Ontario Ministry of Environment and Climate Change; ECST, Environment and Climate Change Canada Science and Technology Branch; NILU, Norwegian Institute for Air Research; NRS, U.S. Forest Service Northern Research Station; CIES, Carey Institute of Ecosystem Studies; RTI, RTI International; WCAL, Central Analytical Laboratory, Wisconsin State Laboratory of Hygiene; UNAM, Universidad Nacional Autonoma de Mexico; all units in milligrams per liter except hydrogen ion (microequivalents per liter) and specific conductance (microsiemens per centimeter at 25 degrees Celsius); overall $f$-psig, $f$-pseudosigma for all participating laboratories; median diff., median of differences between each laboratory's individual results and the most probable value during $2018 ; f$-psig ratio, ratio of each individual laboratory's $f$-pseudosigma to the overall $f$-pseudosigma; sign test $p$-value, probability of rejecting the null hypothesis: "The true median of the differences between laboratory results and the most probable value is zero," when true; values are shaded where median bias is greater than the method detection limit (table 3 ) and statistically significant $(\alpha=0.05)$ (Kanji, 2006); Spec. cond, specific conductance; - , not calculated; <, less than]

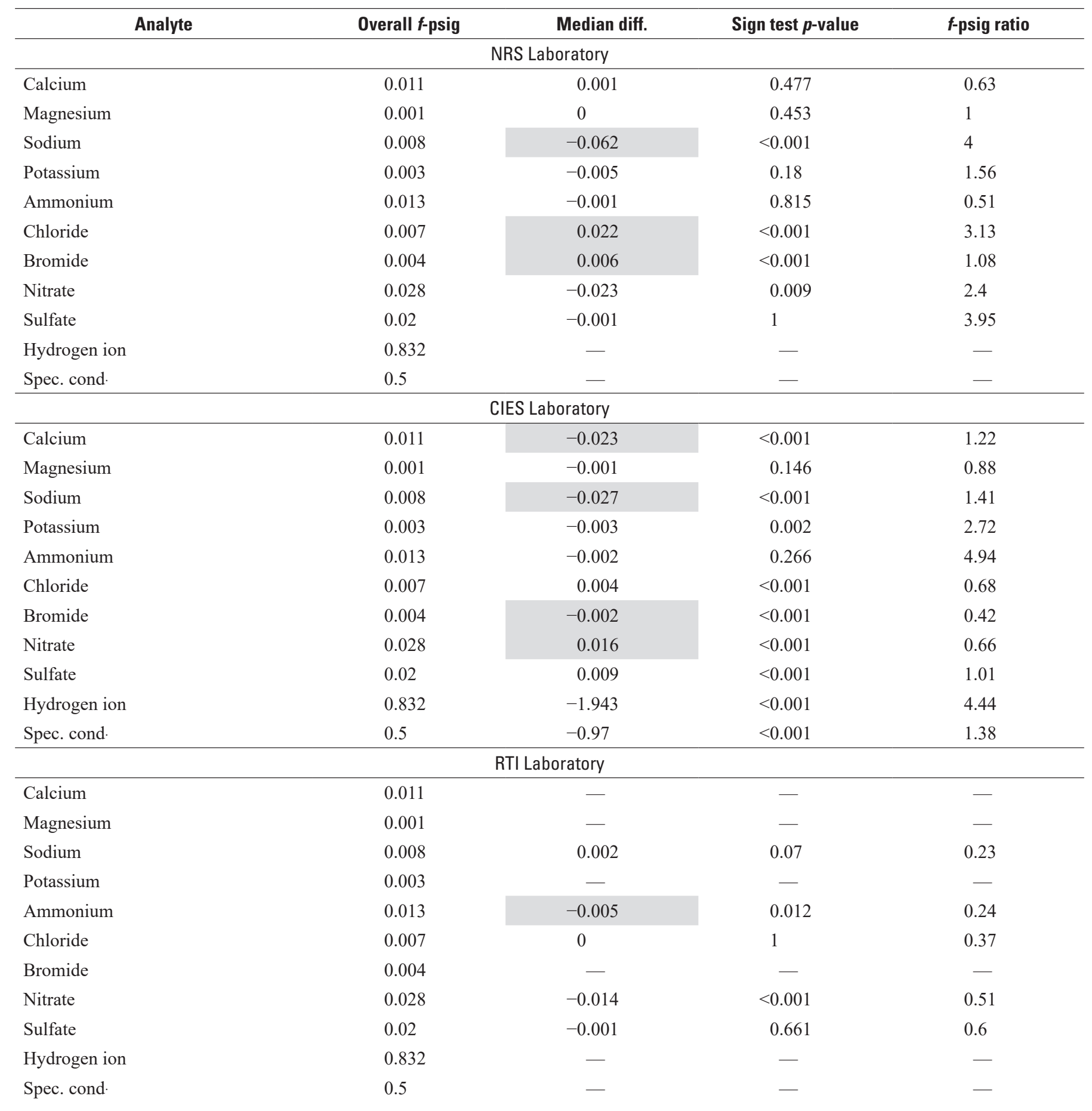


Table 5. Median differences between reported constituent concentrations and most probable values for synthetic wet-deposition samples, 2018 interlaboratory comparison program.-Continued

[ACAP, Asia Center for Air Pollution Research; ICAL, Central Analytical Laboratory, Illinois State Water Survey; WOOD, Wood Group; MOECC, Ontario Ministry of Environment and Climate Change; ECST, Environment and Climate Change Canada Science and Technology Branch; NILU, Norwegian Institute for Air Research; NRS, U.S. Forest Service Northern Research Station; CIES, Carey Institute of Ecosystem Studies; RTI, RTI International; WCAL, Central Analytical Laboratory, Wisconsin State Laboratory of Hygiene; UNAM, Universidad Nacional Autonoma de Mexico; all units in milligrams per liter except hydrogen ion (microequivalents per liter) and specific conductance (microsiemens per centimeter at 25 degrees Celsius); overall $f$-psig, $f$-pseudosigma for all participating laboratories; median diff., median of differences between each laboratory's individual results and the most probable value during 2018; $f$-psig ratio, ratio of each individual laboratory's $f$-pseudosigma to the overall $f$-pseudosigma; sign test $p$-value, probability of rejecting the null hypothesis: "The true median of the differences between laboratory results and the most probable value is zero," when true; values are shaded where median bias is greater than the method detection limit (table 3) and statistically significant $(\alpha=0.05)$ (Kanji, 2006); Spec. cond, specific conductance; - , not calculated; <, less than]

\begin{tabular}{|c|c|c|c|c|}
\hline Analyte & Overall $f$-psig & Median diff. & Sign test $p$-value & $f$-psig ratio \\
\hline \multicolumn{5}{|c|}{ WCAL Laboratory } \\
\hline Calcium & 0.011 & 0.003 & 0.002 & 0.43 \\
\hline Magnesium & 0.001 & 0 & 0.219 & 1 \\
\hline Sodium & 0.008 & 0 & 0.503 & 0.36 \\
\hline Potassium & 0.003 & -0.001 & 0.109 & 0.67 \\
\hline Ammonium & 0.013 & -0.001 & 0.144 & 0.47 \\
\hline Chloride & 0.007 & -0.008 & $<0.001$ & 0.95 \\
\hline Bromide & 0.004 & 0.006 & 0.078 & 0.83 \\
\hline Nitrate & 0.028 & -0.002 & 1 & 1.33 \\
\hline Sulfate & 0.02 & -0.004 & 0.058 & 0.67 \\
\hline Hydrogen ion & 0.832 & 1.326 & 0.001 & 3.37 \\
\hline Spec. cond. & 0.5 & -0.05 & 0.401 & 0.36 \\
\hline \multicolumn{5}{|c|}{ UNAM Laboratory } \\
\hline Calcium & 0.011 & -0.005 & 0.154 & 3.63 \\
\hline Magnesium & 0.001 & 0.006 & 0.004 & 10.13 \\
\hline Sodium & 0.008 & -0.012 & 0.442 & 3.55 \\
\hline Potassium & 0.003 & -0.002 & 1 & 6.44 \\
\hline Ammonium & 0.013 & -0.01 & 0.001 & 2.47 \\
\hline Chloride & 0.007 & -0.011 & $<0.001$ & 3.71 \\
\hline Bromide & 0.004 & - & - & - \\
\hline Nitrate & 0.028 & -0.023 & $<0.001$ & 1.13 \\
\hline Sulfate & 0.02 & 0.025 & $<0.001$ & 1.54 \\
\hline Hydrogen ion & 0.832 & 0.264 & 0.003 & 0.72 \\
\hline Spec. cond & 0.5 & -0.15 & 0.002 & 0.77 \\
\hline
\end{tabular}

measurements indicate generally consistent agreement with MPVs for the ICAL results, but there appears to be a solutionspecific bias only for the synthetic precipitation samples for the WCAL results. The WCAL results for $\mathrm{pH}$ indicate little to no bias for the natural precipitation samples. Meanwhile, specific conductance results for ICAL appear positively biased across all solutions, especially for solution SP2B, while the WCAL specific conductance results indicate no bias. These seemingly solution-specific effects had never been observed in this interlaboratory-comparison program's results.

Analyte determinations that exceeded the control limits ( $\pm 3 f$-psig) for ICAL during 2017-18 include ammonium (1), nitrate (2), sulfate (1), specific conductance (7), and hydrogen ion (5). Analyte determinations that exceeded the control limits for WCAL during 2017-18 include calcium (1), magnesium (1), sodium (1), potassium (1), chloride (1), bromide (1), nitrate (10), sulfate (3), and hydrogen ion (21). Determinations of bias and variability in bromide results are less reliable than for other analytes because MPVs for bromide were determined from results of only 4 participating laboratories, compared to 8-10 laboratories for other analytes. Missing data due to samples lost in shipment and partial participation by some laboratories were problematic, especially in 2018.

Results from the interlaboratory comparison program indicate differences in performance for ICAL and WCAL primarily for analysis of nitrate, specific conductance, and $\mathrm{pH}$. 
Table 6. Number of analyte determinations greater than the method detection limits for deionized water samples, 2017-18.

[Participating laboratories: ACAP, Asia Center for Air Pollution Research; CIES, Carey Institute of Ecosystem Studies; ECST, Environment and Climate Change Canada Science and Technology Branch; ICAL, Central Analytical Laboratory, Illinois State Water Survey; MOECC, Ontario Ministry of Environment and Climate Change; NILU, Norwegian Institute for Air Research; NRS, U.S, Department of Agriculture Forest Service Northern Research Service; RTI, RTI International; UNAM, Universidad Nacional Autonoma de Mexico; AMEC/WOOD, AMEC Foster-Wheeler/Wood Group, Inc.; WCAL, Central Analytical Laboratory, Wisconsin State Laboratory of Hygiene; NP, laboratory not participating in 2017; - , no data]

\begin{tabular}{|c|c|c|c|c|c|c|c|c|c|c|c|}
\hline \multirow{3}{*}{ Analyte } & \multicolumn{11}{|c|}{ Number of determinations greater than analytical detection limits for four blank samples } \\
\hline & \multirow[b]{2}{*}{ ACAP } & \multicolumn{10}{|c|}{2017 Participating laboratories } \\
\hline & & CIES & ECST & ICAL & MOECC & NILU & NRS & RTI & UNAM & WCAL & AMEC/WOOD \\
\hline Calcium & 0 & 0 & 0 & 0 & 1 & 0 & 0 & - & 0 & NP & 0 \\
\hline Magnesium & 2 & 2 & 0 & 0 & 0 & 0 & 0 & - & 0 & NP & 0 \\
\hline Potassium & 0 & 0 & 0 & 2 & 1 & 0 & 0 & - & 0 & NP & 0 \\
\hline Ammonium & 0 & 0 & 0 & 2 & 2 & 0 & 0 & - & 0 & NP & 0 \\
\hline Chloride & 2 & 3 & 0 & 0 & 0 & 0 & 3 & 0 & 0 & NP & 0 \\
\hline Bromide & - & 0 & - & 0 & - & - & 0 & - & - & NP & - \\
\hline Nitrate & 1 & 3 & 0 & 0 & 1 & 0 & 2 & 0 & 0 & NP & 0 \\
\hline Magnesium & 4 & 0 & 0 & 1 & 0 & 0 & 0 & - & 0 & 1 & 0 \\
\hline Sodium & 3 & 0 & 1 & 0 & 0 & 0 & 0 & 0 & 0 & 0 & 0 \\
\hline Potassium & 3 & 0 & 2 & 2 & 1 & 0 & 1 & 0 & 0 & 0 & 0 \\
\hline Ammonium & 2 & 0 & 0 & 1 & 3 & 0 & 0 & 0 & 0 & 0 & 0 \\
\hline Chloride & 2 & 1 & 0 & 1 & 2 & 0 & 3 & 0 & 0 & 0 & 0 \\
\hline Bromide & - & 0 & - & 0 & - & - & 0 & - & - & 0 & - \\
\hline Nitrate & 2 & 4 & 0 & 0 & 2 & 0 & 4 & 0 & 0 & 0 & 0 \\
\hline Sulfate & 2 & 2 & 0 & 0 & 2 & 0 & 4 & 0 & 0 & 0 & 0 \\
\hline
\end{tabular}

However, a special study was conducted by the NADP Quality Assurance Advisory Group with assistance from the PCQA to compare ICAL and WCAL performance and verify readiness of the WCAL to assume the role of the CAL for NADP. Results of that study are contained in the internal NADP Central Analytical Laboratory Readiness Verification Report (RVP). Results for 75 spiked natural matrix split samples analyzed by the ICAL and WCAL are summarized in table 8 . Median absolute percent differences for the split samples were less than 10 percent for all analytes except potassium (12 percent). Furthermore, the RVP results indicated a negative bias for WCAL results relative to ICAL results for nitrate and hydrogen ion concentrations, which is opposite of the results presented in this report. Therefore, control charts for 2018 shown herein should be used with caution as representative indicators of laboratory bias relative to the MPVs. Nonetheless, continued monitoring of the potential differences in ICAL and WCAL relative bias is required to ensure that potential shifts in the precipitation chemistry record can be appropriately attributed to either true environmental signals or shifts in sample collection and analysis methodology.

\section{Colocated Sampler Program}

For water years 2017-18, the colocated sampler program evaluated the variability of NTN data obtained with $\mathrm{N}-\mathrm{CON}$ collectors. Colocated N-CON collectors were operated at NTN sites CO11 and $11 \mathrm{CO}$ at the Arvada Community Gardens, Arvada, Colorado. A single OTT Pluvio-2 precipitation gage measured and recorded precipitation depth as well as the operation of the N-CON collectors. Colocated sites were operated using identical field and laboratory sample-collection and sample-analysis procedures (Wisconsin State Laboratory of Hygiene, 2019).

Weekly precipitation chemistry data from colocated sites were analyzed for differences between the CO11 and $11 \mathrm{CO}$ weekly analyte concentrations. Only valid data 
Table 7. Number of analyte determinations outside $\pm 3 f$-pseudosigma statistical control limits, by participating laboratory, 2017-18.

[n, number of samples analyzed; $\mathrm{Ca}$, calcium; $\mathrm{Mg}$, magnesium; $\mathrm{Na}$, sodium; $\mathrm{K}$, potassium; $\mathrm{NH}_{4}$, ammonium; $\mathrm{Cl}$, chloride; $\mathrm{NO}_{3}$, nitrate; $\mathrm{SO}_{4}$, sulfate; $\mathrm{Br}$, bromide, Sc, specific conductance at 25 degrees Celsius; H, hydrogen ion concentration from pH; ACAP, Asia Center for Air Pollution Research; CIES, Carey Institute of Ecosystem Studies; ECST, Environment and Climate Change Canada Science and Technology Branch; ICAL, Central Analytical Laboratory, Illinois State Water Survey; MOECC, Ontario Ministry of Environment and Climate Change; NILU, Norwegian Institute for Air Research; NRS, U.S. Department of Agriculture Forest Service Northern Research Service; RTI, RTI International; UNAM, Universidad Nacional Autonoma de Mexico; WCAL, Central Analytical Laboratory, Wisconsin State Laboratory of Hygiene; AMEC/WOOD, AMEC Foster-Wheeler / Wood Group, Inc.; —, no data; *, n=9 ]

\begin{tabular}{lcrrrrrrrrrrr}
\hline \multicolumn{1}{c}{ Laboratory } & $\mathbf{n}$ & $\mathbf{C a}$ & $\mathbf{M g}$ & $\mathbf{N a}$ & $\mathbf{K}$ & $\mathbf{N H}_{\mathbf{4}}$ & $\mathbf{C l}$ & $\mathbf{N O}_{\mathbf{3}}$ & $\mathbf{S O}_{\mathbf{4}}$ & $\mathbf{B r}$ & $\mathbf{S c}$ & $\mathbf{H}$ \\
\hline ACAP & & & & & 2017 & & & & & & & \\
CIES & 44 & 5 & 18 & 1 & 8 & 1 & 4 & 4 & 6 & - & 0 & 4 \\
ECST & 44 & 4 & 0 & 14 & 3 & 2 & 5 & 6 & 5 & 0 & 10 & 29 \\
ICAL & 44 & 2 & 2 & 1 & 1 & 1 & 2 & 1 & 3 & - & 1 & 1 \\
MOECC & 44 & 0 & 0 & 0 & 0 & 0 & 0 & 1 & 1 & 0 & 6 & 0 \\
NILU & 42 & 13 & 1 & 4 & 4 & 1 & 15 & 0 & 5 & - & 0 & 19 \\
NRS & 44 & 2 & 3 & 0 & 3 & 0 & 0 & 7 & 7 & - & 2 & 5 \\
RTI & 40 & 1 & 1 & 12 & 2 & 2 & 26 & 2 & 11 & 0 & 1 & 3 \\
UNAM & 44 & - & - & - & - & - & 0 & 1 & 0 & - & - & - \\
WCAL & 40 & 7 & 35 & 9 & 34 & 5 & 4 & 2 & 3 & - & - & 8 \\
AMEC/WOOD & 4 & 1 & 1 & 0 & 1 & 0 & 0 & 0 & 0 & 0 & 0 & 7 \\
\hline ACAP & 40 & 0 & 0 & 2 & 0 & 0 & 0 & 1 & 1 & 0 & 0 & 4 \\
CIES & 43 & 0 & 8 & 0 & 0 & 3 & 2 & 0 & 4 & - & 0 & 13 \\
ECST & 44 & 10 & 0 & 6 & 8 & 16 & 2 & 1 & 3 & 3 & 17 & 6 \\
ICAL & 41 & 0 & 0 & 0 & 0 & 1 & 0 & 0 & 3 & - & 2 & 0 \\
MOECC & 44 & 0 & 0 & 0 & 0 & 1 & 0 & 1 & 0 & 0 & 1 & 5 \\
NILU & 41 & 16 & 9 & 1 & 4 & 2 & 0 & 8 & 3 & - & 2 & 5 \\
NRS & 44 & 1 & 4 & 1 & 6 & 3 & 4 & 7 & 8 & - & 0 & 0 \\
RTI & 34 & 0 & 1 & 9 & 4 & 1 & 12 & 14 & 14 & 3 & 2 & 1 \\
UNAM & 44 & $8^{*}$ & $4 *$ & $0 *$ & $0 *$ & $0 *$ & 0 & 1 & 1 & - & - & - \\
WCAL & 32 & 17 & 21 & 6 & 14 & 8 & 14 & 2 & 4 & - & - & 2 \\
WOOD & 44 & 0 & 0 & 1 & 0 & 0 & 2 & 10 & 3 & 1 & 0 & 14 \\
\hline & 44 & 0 & 2 & 2 & 3 & 2 & 4 & 0 & 3 & - & 0 & 8 \\
\hline
\end{tabular}

(quality rating codes " $\mathrm{A}$ " and "B") identified in the NADP by a laboratory-type code "W" (sufficient volume for complete analysis) and "WI" (volume for incomplete analysis) were used (National Atmospheric Deposition Program, http://nadp.slh.wisc.edu/data/ntn/meta/ntnDataValidation.pdf, last accessed September 20, 2019). Samples flagged as contaminated by NADP were considered prone to a greater error component. For this reason, valid contaminated samples were eliminated from statistical analysis in previous reports. However, eliminating the contaminated samples for water years 2017-18 would have resulted in a limited dataset with only 26 pairs of samples and incomplete seasonal representation for the 2-year period of record. Therefore, all of the 52 valid sample pairs were used for this report regardless of contamination flagging by NADP.
Because annual summaries of NTN data describe wetdeposition chemistry in terms of concentration and deposition, statistical summaries for colocated concentration and deposition measurements are provided. The weekly precipitation depth from the precipitation gage was used to calculate deposition values at the colocated sites by multiplying precipitation-weighted mean concentrations for each analyte in milligrams per liter $(\mathrm{mg} / \mathrm{L})$ by 0.10 multiplied by the precipitation depth in centimeters $(\mathrm{cm})$ to yield deposition in kilograms per hectare $(\mathrm{kg} / \mathrm{ha})$ (Wetherbee and others, 2010).

Concentration differences from paired weekly samples obtained from the colocated collectors were calculated to evaluate variability, which was described by Wetherbee and others (2005b) as the overall error in NTN data. Relative concentration differences were calculated as the CO11 concentrations minus the $11 \mathrm{CO}$ concentrations. Results from these calculations are shown in table 9 . The median weekly 

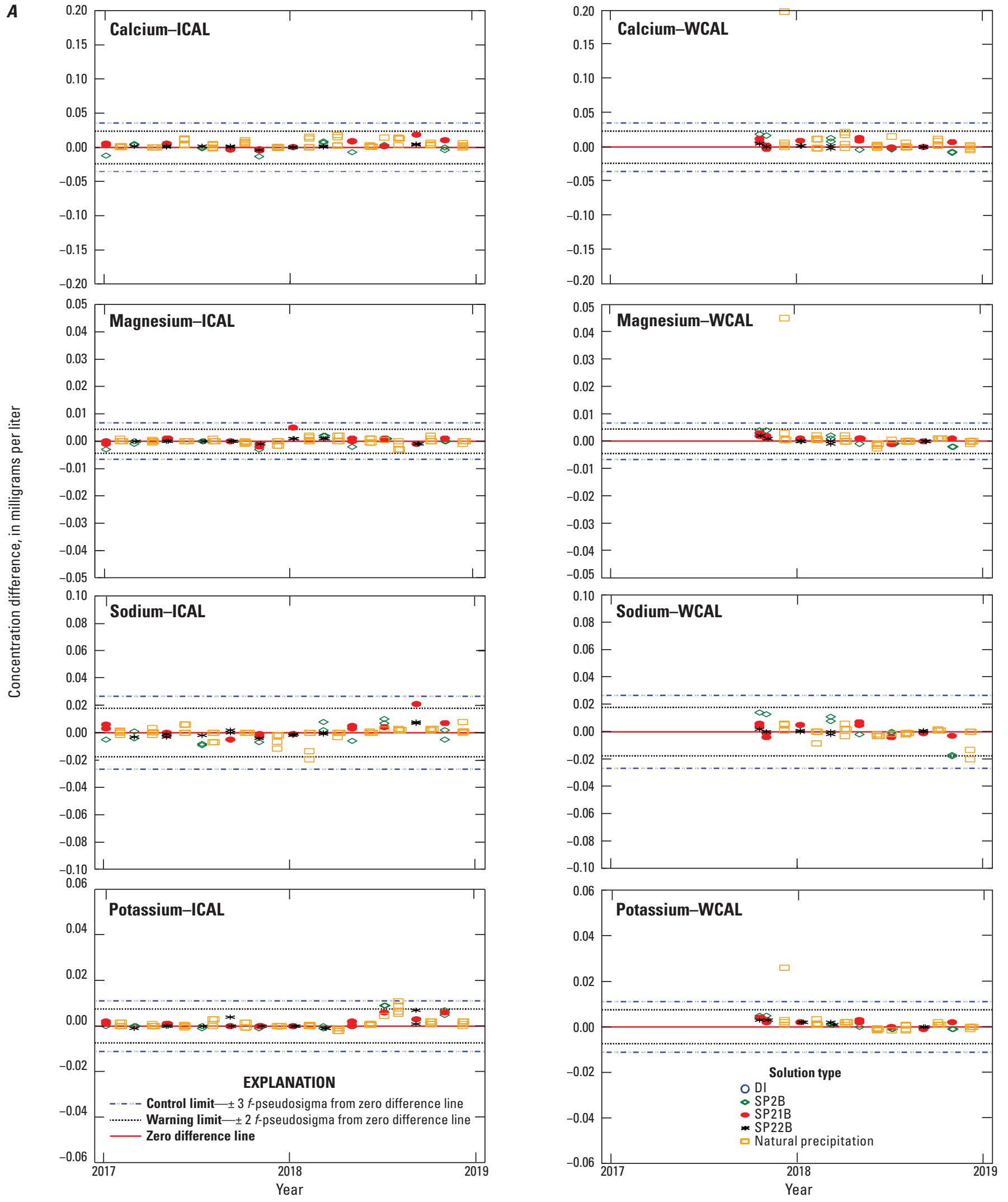

Figure 4. Differences between concentration values reported by the Central Analytical Laboratories and the median concentration values for all participating laboratories in the interlaboratory comparison program for the National Trends Network, 2017-18. 

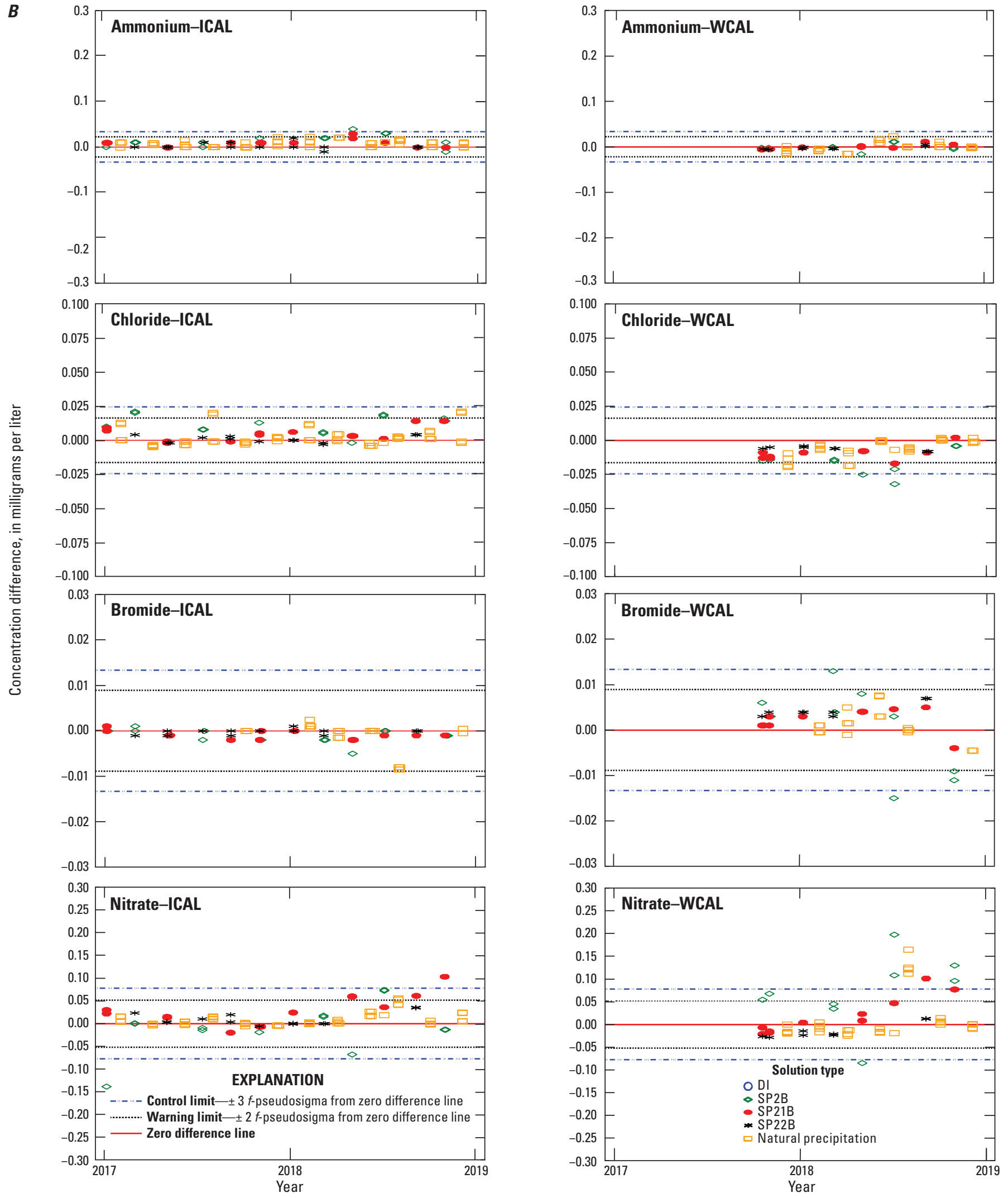

Figure 4. Differences between concentration values reported by the Central Analytical Laboratories and the median concentration values for all participating laboratories in the interlaboratory comparison program for the National Trends Network, 2017-18.Continued 

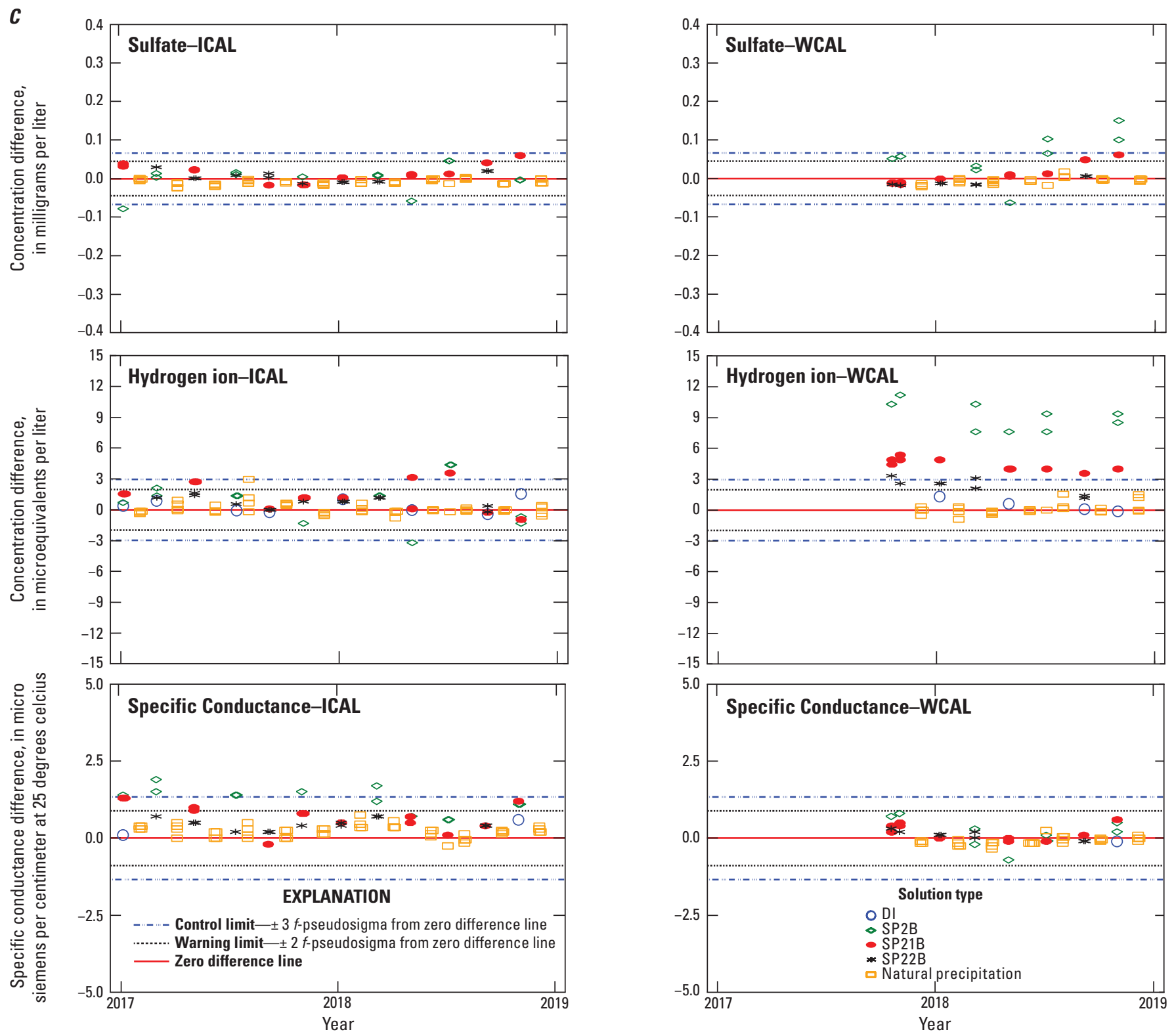

Figure 4. Differences between concentration values reported by the Central Analytical Laboratories and the median concentration values for all participating laboratories in the interlaboratory comparison program for the National Trends Network, 2017-18.Continued

relative differences were small and ranged $0.000-0.005 \mathrm{mg} / \mathrm{L}$ for calcium, magnesium, sodium and potassium (cations), and $0.003-0.020 \mathrm{mg} / \mathrm{L}$ for chloride, nitrate, and sulfate (anions). Median relative differences for both ammonium (0.008-0.022 mg/L) and hydrogen ion (0.009-0.010 microequivalents per liter $[\mu \mathrm{eq} / \mathrm{L}]$ ) as well as specific conductance values $(0.3-1.0$ microseimens per centimeter $[\mu \mathrm{S} / \mathrm{cm}])$ were also considered small (table 9). Median weekly absolute percent differences ranged 7-22 percent for cations, 4-10 percent for anions, 6-9 percent for ammonium, and 9.2-32 percent for hydrogen ion. Median weekly absolute percent differences for sample volume catch were low at 4-5 percent.

Annual deposition absolute percent differences (APD) ranged 8-18 percent for calcium, and were zero for magnesium, sodium, and potassium. Ammonium annual deposition APD ranged 0-12 percent. Annual deposition APD for anions ranged as follows: chloride (12-29 percent), nitrate (2-15 percent), and sulfate ( $0-7$ percent). Annual hydrogenion deposition APD ranged 0-51 percent. Hydrogen-ion 


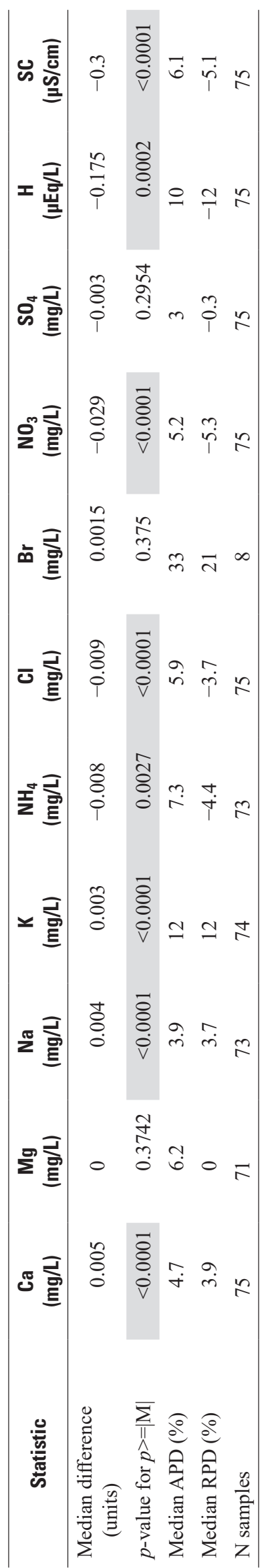

concentrations were low with 35 of the $46 \mathrm{pH}$ measurements greater than $\mathrm{pH}=6$, and percent differences of small hydrogenion concentrations are relatively large.

The event-recorder data for actuation of the collector lids on the colocated $\mathrm{N}-\mathrm{CON}$ collectors are shown in table 10 and include the number of times that the collector lids opened and closed (lid cycles). Table 10 also shows the amount of time that the collectors were open while the precipitation gage detected precipitation (wet exposure) and how long they were open when it did not (dry exposure). The collector sensors play a large role in the data variability and bias (Wetherbee, 2017; Wetherbee and Rhodes, 2013). Dry exposure of NTN samples can lead to sample contamination with dry deposited materials. More than 6 hours of dry exposure causes invalidation of NTN samples.

The APDs for counted lid cycles at CO11/11CO ranged 20-26 percent, indicating that the $11 \mathrm{CO}$ collector cycled 20-26 percent more than the CO11 collector. Wet exposure APD was 1.2-2.1 percent, but dry exposure APD ranged 1.4 percent (2017)-14 percent (2018). The 11CO samples received 13 percent more dry exposure in 2018 than in 2017. The cause of this is unknown. By comparison, the water year 2015-2016 studies at NTN sites OH71/71OH and SD08/08SD indicated APDs of 8-22 percent for lid cycles, 3-10 percent for wet exposure, and 0-26 percent for dry exposure (Wetherbee and Martin, 2018). Despite differences in 2018 performance of the collectors, overall differences in chemical solute concentrations were small.

\section{Mercury Deposition Network Quality Assurance Programs}

The USGS operated a system blank program and an interlaboratory comparison program for the MDN during 2017-18. Protocols for the PCQA external QA programs for MDN are described in detail by Wetherbee and Martin (2016a). The MDN system blank program is similar to the NTN field audit program, whereby the effects of onsite environmental exposure, handling, and shipping on sample contamination are evaluated. The MDN interlaboratory comparison program quantified variability and bias of MDN analytical data provided by the Mercury Analytical Laboratory (HAL) of Eurofins Frontier Global Sciences, Inc., in Bothell, Washington, for 2017-18.

\section{System Blank Program}

The MDN site operators received system blank samples from PCQA during 2017, but no samples were shipped to MDN sites in 2018 to allow for transfer of NADP operations from the Illinois State Water Survey to the Wisconsin State Laboratory of Hygiene. After a week without wet deposition at a site, operators poured one-half of the volume of the system 
Table 9. Median weekly constituent concentration differences and annual deposition differences for colocated N-CON Systems Company, Inc. precipitation collectors at National Atmospheric Deposition Program sites C011 and 11CO for all valid samples, water years 2017-18.

[mg/L, milligram per liter; $\mu \mathrm{eq} / \mathrm{L}$, microequivalent per liter; $\mu \mathrm{S} / \mathrm{cm}$, microsiemens per centimeter at 25 degrees Celsius; mL, milliliter; NA, not applicable ]

\begin{tabular}{|c|c|c|c|c|c|c|c|c|}
\hline \multirow[b]{2}{*}{ Analyte (units) } & \multicolumn{4}{|c|}{ Water year 2017} & \multicolumn{4}{|c|}{ Water year 2018} \\
\hline & $\begin{array}{c}\text { Median } \\
\text { weekly } \\
\text { relative } \\
\text { difference }\end{array}$ & $\begin{array}{c}\text { Median } \\
\text { weekly } \\
\text { absolute } \\
\text { percent } \\
\text { difference }\end{array}$ & $\begin{array}{c}\text { Annual } \\
\text { deposition } \\
\text { absolute } \\
\text { percent } \\
\text { difference }\end{array}$ & $\begin{array}{c}\text { Range of } \\
\text { measured } \\
\text { values }\end{array}$ & $\begin{array}{l}\text { Median } \\
\text { weekly } \\
\text { relative } \\
\text { difference }\end{array}$ & $\begin{array}{c}\text { Median } \\
\text { weekly } \\
\text { absolute } \\
\text { percent } \\
\text { difference }\end{array}$ & $\begin{array}{c}\text { Annual } \\
\text { deposition } \\
\text { absolute } \\
\text { percent } \\
\text { difference }\end{array}$ & $\begin{array}{l}\text { Range of } \\
\text { measured } \\
\text { values }\end{array}$ \\
\hline $\begin{array}{l}\text { Calcium } \\
\text { (mg/L) }\end{array}$ & 0.002 & 4.9 & 18 & $0.058-1.78$ & 0.005 & 7.6 & 8 & $0.080-2.03$ \\
\hline $\begin{array}{l}\text { Magnesium } \\
(\mathrm{mg} / \mathrm{L})\end{array}$ & 0.001 & 7.2 & 0 & $0.007-0.183$ & 0.001 & 10 & 0 & $0.008-0.260$ \\
\hline $\begin{array}{l}\text { Sodium } \\
\qquad(\mathrm{mg} / \mathrm{L})\end{array}$ & 0.002 & 11 & 0 & $0.003-1.29$ & 0.002 & 7 & 0 & $0.005-2.44$ \\
\hline $\begin{array}{l}\text { Potassium } \\
\qquad(\mathrm{mg} / \mathrm{L})\end{array}$ & 0 & 22 & 0 & $0.006-0.164$ & 0 & 22 & 0 & $0.010-0.179$ \\
\hline $\begin{array}{l}\text { Chloride } \\
(\mathrm{mg} / \mathrm{L})\end{array}$ & 0.003 & 10 & 29 & $0.013-2.42$ & 0.005 & 10 & 12 & $0.032-3.65$ \\
\hline $\begin{array}{l}\text { Nitrate } \\
\qquad(\mathrm{mg} / \mathrm{L})\end{array}$ & 0.02 & 4.3 & 15 & $0.253-10.7$ & 0.02 & 3.8 & 2.2 & $0.356-3.85$ \\
\hline $\begin{array}{l}\text { Sulfate } \\
\text { mg/L) }\end{array}$ & 0.012 & 9 & 7.4 & $0.097-4.88$ & 0.006 & 5.2 & 0 & $0.182-11.77$ \\
\hline $\begin{array}{l}\text { Hydrogen-ion } \\
\quad(\mu \mathrm{eq} / \mathrm{L})\end{array}$ & 0.01 & 9.2 & 51 & $0.158-7.08$ & 0.009 & 32 & 0 & $0.112-3.72$ \\
\hline $\begin{array}{l}\text { Specific conductance } \\
\qquad(\mu \mathrm{S} / \mathrm{cm})\end{array}$ & 0.3 & 7.5 & NA & $2.8-37$ & 1 & 5.3 & NA & $5.6-37$ \\
\hline
\end{tabular}

blank solution through the glass sample train. The glass sample train consists of the collector funnel, which collects the precipitation sample, and a thistle tube, which drains the precipitation into the sample bottle. The solution that washed through the sample train is called the system blank sample, and the solution remaining in the original sample bottle is called the bottle sample. Both system blank and bottle samples were sent together to HAL for total mercury $(\mathrm{Hg})$ analysis.

Of the 91 active MDN sites that received system blank samples in 2017, 55 sites either processed samples or returned a postcard to PCQA indicating no dry weeks during the year. In all, 41 system blank samples were processed with accompanying bottle samples, and four sites with no dry weeks submitted unopened bottle samples, which served as trip blanks. The trip blanks were analyzed by the HAL for total Hg concentrations, all of which were less than the detection limit. The HAL provided the system blank data to the PCQA, and system sample minus bottle sample differences were calculated by the USGS. Data for 123 system blank sample pairs were received by PCQA from the HAL during 2015-18.

\section{Network Maximum Contamination Levels for Mercury}

The NMCLs for total $\mathrm{Hg}$ were calculated from the system blank data using a 3-year moving window starting with 2004-06. MDN NMCL for total $\mathrm{Hg}$ decreased from $1.098 \mathrm{ng} / \mathrm{L}$ for the $2014-16$ period to $1.023 \mathrm{ng} / \mathrm{L}$ for the 2015-17 period (table 11). Thus, the maximum contamination in MDN samples during 2015-17 was not greater than $1.023 \mathrm{ng} / \mathrm{L}$ with 90-percent confidence, and no more than 10 percent of the MDN samples had contamination concentrations exceeding $1.023 \mathrm{ng} / \mathrm{L}$ with 90 -percent confidence. This 
Table 10. Event recorder data summary for colocated N-CON Systems Company, Inc., precipitation collectors at National Atmospheric Deposition Program sites C011 and 11C0, water years 2017-18.

[Lid cycle, number of times collector opened and then closed; Wet exposure, time that collector is open to collect precipitation when rain gage confirms measurement of precipitation; Dry exposure, time that collector is open when rain gage does not indicate measurement of precipitation; cm, centimeter; APD, absolute percent difference]

\begin{tabular}{lccccc}
\hline Water year & Site identifier & Lid cycles & $\begin{array}{c}\text { Wet exposure } \\
\text { (hours) }\end{array}$ & $\begin{array}{c}\text { Dry exposure } \\
\text { (hours) }\end{array}$ & $\begin{array}{c}\text { Precipitation depth } \\
\text { (cm) }\end{array}$ \\
\hline 2017 & CO11 & 1,917 & 239.7 & 174.4 & 34.04 \\
& 11 CO & 2,480 & 236.8 & 172 & \\
2018 & APD: & 26 & 1.2 & 1.4 & 33.15 \\
& CO11 & 1,937 & 221.3 & 161.2 & \\
& 11CO & 2,369 & 216.7 & 140 & \\
\hline
\end{tabular}

Table 11. Three-year moving network maximum contamination levels and 90-percent upper confidence limits at the 50th, 75th, and 90th percentiles of total mercury contamination mass in system blank samples, 2004-17.

[\%, percent; UCL, upper confidence limit; Hg, total mercury; ng Hg, nanogram of mercury; ng Hg/L, nanogram of mercury per liter; nd, no data collected in 2018]

\begin{tabular}{|c|c|c|c|c|}
\hline \multirow{3}{*}{ 3-year period } & \multirow{3}{*}{$\begin{array}{l}\text { Network maximum } \\
\text { contamination level1 } \\
\text { (ng total } \mathrm{Hg} / \mathrm{L} \text { ) }\end{array}$} & \multicolumn{3}{|c|}{$\begin{array}{l}\text { 90\% UCLs on percentiles of total } \mathrm{Hg} \text { contamination mass in } \\
\text { system blank samples (ng Hg) }\end{array}$} \\
\hline & & \multicolumn{3}{|c|}{ Percentiles } \\
\hline & & 50th & 75th & 90th 2 \\
\hline 2004-06 & 0.412 & 0.005 & 0.095 & 0.095 \\
\hline 2005-07 & 1.067 & 0.018 & 0.067 & 0.136 \\
\hline 2006-08 & 2.17 & 0.04 & 0.1 & 0.233 \\
\hline 2007-09 & 3.476 & 0.06 & 0.12 & 0.325 \\
\hline 2008-10 & 4.26 & 0.07 & 0.152 & 0.325 \\
\hline 2009-11 & 1.588 & 0.068 & 0.14 & 0.285 \\
\hline 2010-12 & 1.771 & 0.065 & 0.12 & 0.26 \\
\hline 2011-13 & 1.871 & 0.052 & 0.097 & 0.47 \\
\hline 2012-14 & 1.871 & 0.045 & 0.095 & 0.536 \\
\hline $2013-15$ & 1.787 & 0.036 & 0.068 & 0.115 \\
\hline 2014-16 & 1.098 & 0.034 & 0.064 & 0.094 \\
\hline 2015-17 & 1.023 & 0.034 & 0.068 & 0.101 \\
\hline 2016-18 & nd & nd & nd & nd \\
\hline
\end{tabular}

${ }^{1}$ Defined as the 90-percent UCL on 90th percentile of system-blank Hg contamination concentrations.

2Defined as the maximum contamination mass per sample. 
concentration is approximately equal to the first percentile of all MDN weekly Hg concentrations from 2016 to 18 (Robert Larson, NADP Program Office, Wisconsin State Laboratory of Hygiene, written commun., 2019).

\section{Mass of Mercury Contamination}

The mass of Hg contamination in each system blank sample was calculated as follows:

$$
\begin{gathered}
H g \text { contamination }(\text { nanograms })=\left(\left[\mathrm{Hg}_{S B}\right]\right. \\
\left.\times \text { Volume }_{S B}\right)-\left(\left[\mathrm{Hg}_{\text {Bot }}\right] \times \text { Volume }_{B o t}\right)
\end{gathered}
$$

where

$\left[\mathrm{Hg}_{S B}\right] \quad$ is the total $\mathrm{Hg}$ concentration in system blank sample, in nanograms per liter;

Volume $_{S B}$ is the volume of system blank sample, in liters;

$\left[\mathrm{Hg}_{B o t}\right]$ is the total $\mathrm{Hg}$ concentration in the bottle sample, in nanograms per liter; and

Volume $_{B o t}$ is the volume of the bottle sample, in liters.

Next, the UCLs of the percentiles of the system sample minus bottle sample $\mathrm{Hg}$ mass differences were calculated. Based on the 90 percent UCL on the 90th percentile of total $\mathrm{Hg}$ contamination mass, the maximum estimated contaminant mass per sample increased slightly from $0.094 \mathrm{ng} \mathrm{Hg}$ during 2014-16 to 0.101 ng Hg during 2015-17 (table 11).

\section{Mercury Deposition Network Interlaboratory Comparison Program}

The objective of the MDN interlaboratory comparison program is to estimate the variability and bias of HAL analytical data in comparison with results from analytical laboratories supporting various monitoring networks, not accounting for the different onsite protocols used by different monitoring networks. Eight laboratories participated in the program during the study period: (1) HAL at Eurofins Frontier Global Sciences, Inc., in Bothell, Washington; (2) Chinese Academy of Sciences, Institute of Geochemistry (CASIG), in Guiyang, People's Republic of China; (3) Department of Atmospheric Science, National Central University (DASNCU), in Jhong-Li District, Taoyuan City, Taiwan; (4) Flett Research, Ltd. (FRL), in Winnipeg, Manitoba, Canada; (5) Swedish Environmental Institute (IVL) in Goteborg, Sweden; (6) Quebec Laboratory for Environmental Testing (LEEQ or QLET) in Montreal, Quebec, Canada; (7) North Shore Analytical, Inc., (NSA) in Duluth, Minnesota; and (8) USGS Mercury Research Laboratory (WML) in Middleton, Wisconsin. During 2018, the scope of the program was reduced to 6 laboratories, which included HAL, DASNCU, FRL, IVL, and WML to accommodate transfer of NADP operations from the ISWS to the WSLH. All laboratories analyzed the water samples for low levels of Hg using atomic fluorescence spectrometry methods similar to U.S. Environmental Protection Agency Method 1631 (U.S. Environmental Protection Agency, 2002).

During 2017, each participating laboratory received two samples per month consisting of 1-percent (volume:volume) hydrochloric acid blanks and mercuric nitrate spiked at four different concentrations in a 1-percent hydrochloric acid matrix. During 2018, each participating laboratory received two to four samples quarterly. The laboratories were instructed to analyze the samples as soon as they were received to promote accurate time representation of the data. All samples were single-blind samples, where the chemical analyst knew that the sample was a quality-control sample but did not know the total $\mathrm{Hg}$ concentrations of the samples. The medians of all the concentration values obtained from the participating laboratories were considered to be MPVs, which are listed in table 12.

\section{Control Charts}

Total $\mathrm{Hg}$ analysis data submitted by each laboratory were compared to MPVs for each of the four solutions. Differences between reported results and MPVs were plotted on annual control charts, which were delivered to each laboratory by PCQA. Control charts include warning limits placed at $\pm 2 f$-psig and control limits at $\pm 3 f$-psig from the zero-difference line during the study period. Values outside the control limits represent periods when a laboratory's analyses were considered to be out of statistical control.

The HAL's control chart for the 2017-18 interlaboratory comparison analyses shows that all results are within statistical control ( $\pm 3 f$-psig) except for one result for MP4 in the fourth quarter of 2018. One result for MP2 was outside the positive warning limit (+2f-psig) during 2017 (fig. 5). No bias in the HAL results was evident from the control chart.

\section{Interlaboratory Variability and Bias}

Each laboratory's results for variability and bias are summarized in table 13. Methods for evaluation of the interlaboratory variability and bias for the MDN interlaboratory comparison program are analogous to those for the NTN interlaboratory comparison program. The $f$-psig ratio was computed as shown in equation 6 and expressed as a percentage for each laboratory, whereby an $f$-psig ratio larger than 100 percent indicates that results provided by a laboratory exhibited higher variability than the overall variability among the participating laboratories; a ratio smaller than 100 percent indicates less variability than overall. The arithmetic signs of the median differences indicate whether total mercury analysis results were positively or negatively biased. Interlaboratory bias was evaluated for statistical significance using the sign test for location of a median (Kanji, 2006; Wetherbee and others, 2013). 
Table 12. Most probable values for total mercury in four solutions and hydrochloric acid blank samples used for the U.S. Geological Survey Mercury Deposition Network interlaboratory comparison program, 2017-18.

[Hg, total mercury; MPV, most probable value; ng/L, nanogram per liter; \%, percent; $\mathrm{HCl}$, hydrochloric acid; BLANK, mercury-free de-ionized water with $1 \% \mathrm{HCl}$ by volume; MP1-MP4, mercuric nitrate standard diluted to target concentrations in $1 \% \mathrm{HCl}$; Blank MPVs estimated by Kaplan-Meier method in R-NADA package because of large number of censored values]

\begin{tabular}{lc}
\hline \multicolumn{1}{c}{ Solution identifier } & $\begin{array}{c}\text { Total Hg concentration MPV } \\
\text { (ng/L) }\end{array}$ \\
\hline 1\% HCl BLANK & 2017 \\
MP1 & 0.02 \\
MP2 & 5.9 \\
MP3 & 8.7 \\
MP4 & 14.3 \\
\hline & 2018 \\
\hline \% HCl BLANK & 20.4 \\
MP1 & \\
MP2 & 0.05 \\
MP3 & 5.41 \\
MP4 & 8.33 \\
\hline
\end{tabular}

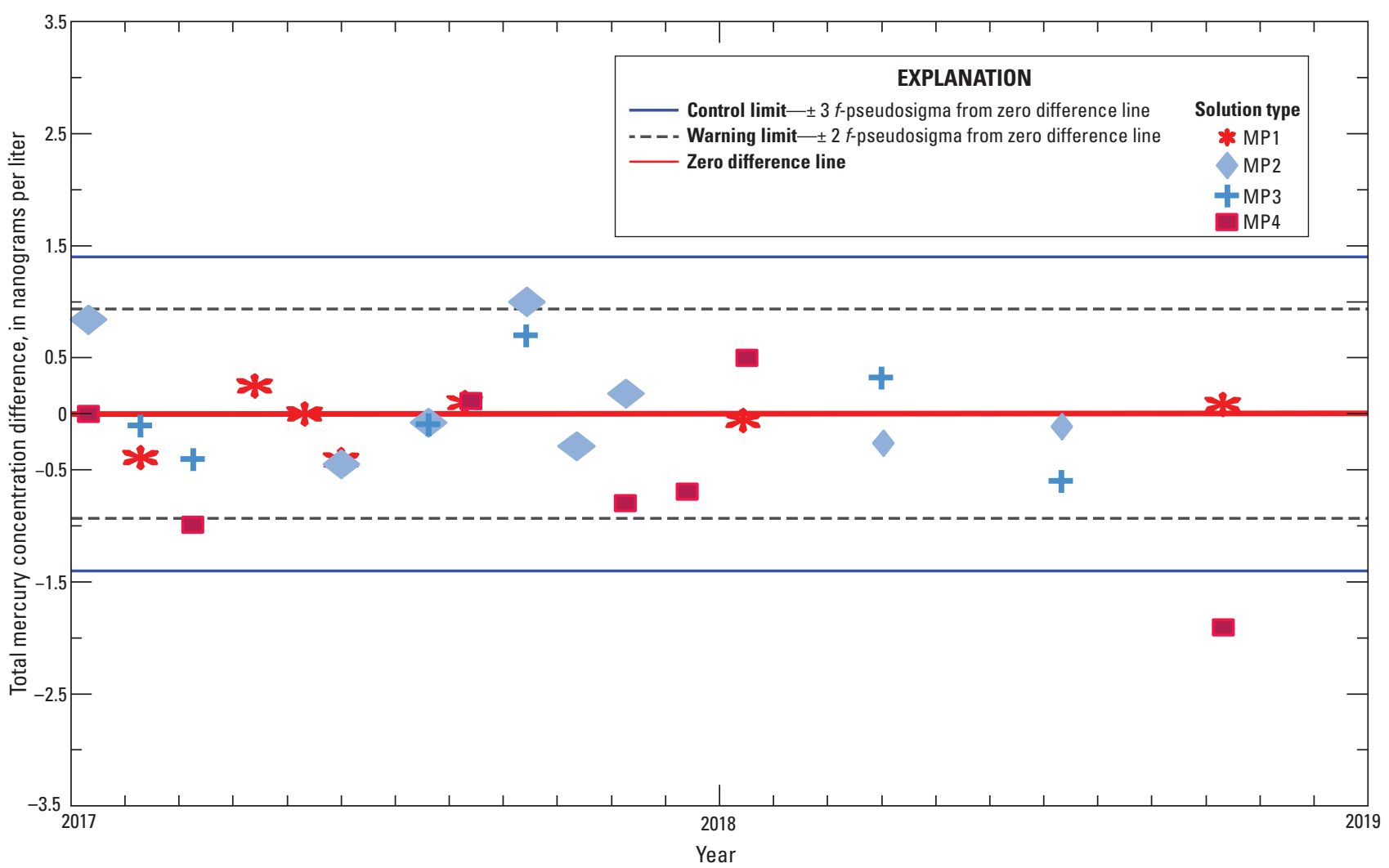

Figure 5. Differences between total mercury concentrations reported by the Mercury Analytical Laboratory, Eurofins Frontier Global Sciences, Inc., and the median concentration values for all participating laboratories in the interlaboratory comparison program for the Mercury Deposition Network, 2017-18. Data are for test solutions MP1, MP2, MP3, and MP4. 
Table 13. Differences between reported concentrations and most probable values for total mercury determinations, Mercury Deposition Network interlaboratory comparison program, 2017-18.

[ng/L, nanogram per liter; overall $f$-psig, $f$-pseudosigma for all participating laboratories; median diff., median of differences between each laboratory's individual results and the most probable values for each solution; sign test $p$-value, probability of rejecting the null hypothesis: "The true median of the differences between laboratory results and the most probable value is zero," when true; $f$-psig ratio, ratio of each individual laboratory's $f$-pseudosigma to the overall $f$-pseudosigma; sign test $p$-value, probability of rejecting the null hypothesis: "The true median of the differences between laboratory results and the most probable value is zero," when true; HAL, Mercury Analytical Laboratory at Eurofins Frontier Global Sciences, Inc.; CASIG, Chinese Academy of Sciences, Institute of Geochemistry; DASNCU, Department of Atmospheric Sciences, National Central University (Taiwan); FRL, Flett Research, Ltd.; IVL, Swedish Environmental Research Institute; LEEQ, Quebec Laboratory of Environmental Testing; NSA, North Shore Analytical, Inc.; WML, U.S. Geological Survey Wisconsin Mercury Laboratory; n.d., no data; <, less than; statistical warning limits are \pm 2 overall $f$-psig, statistical control limits are \pm 3 overall $f$-psig]

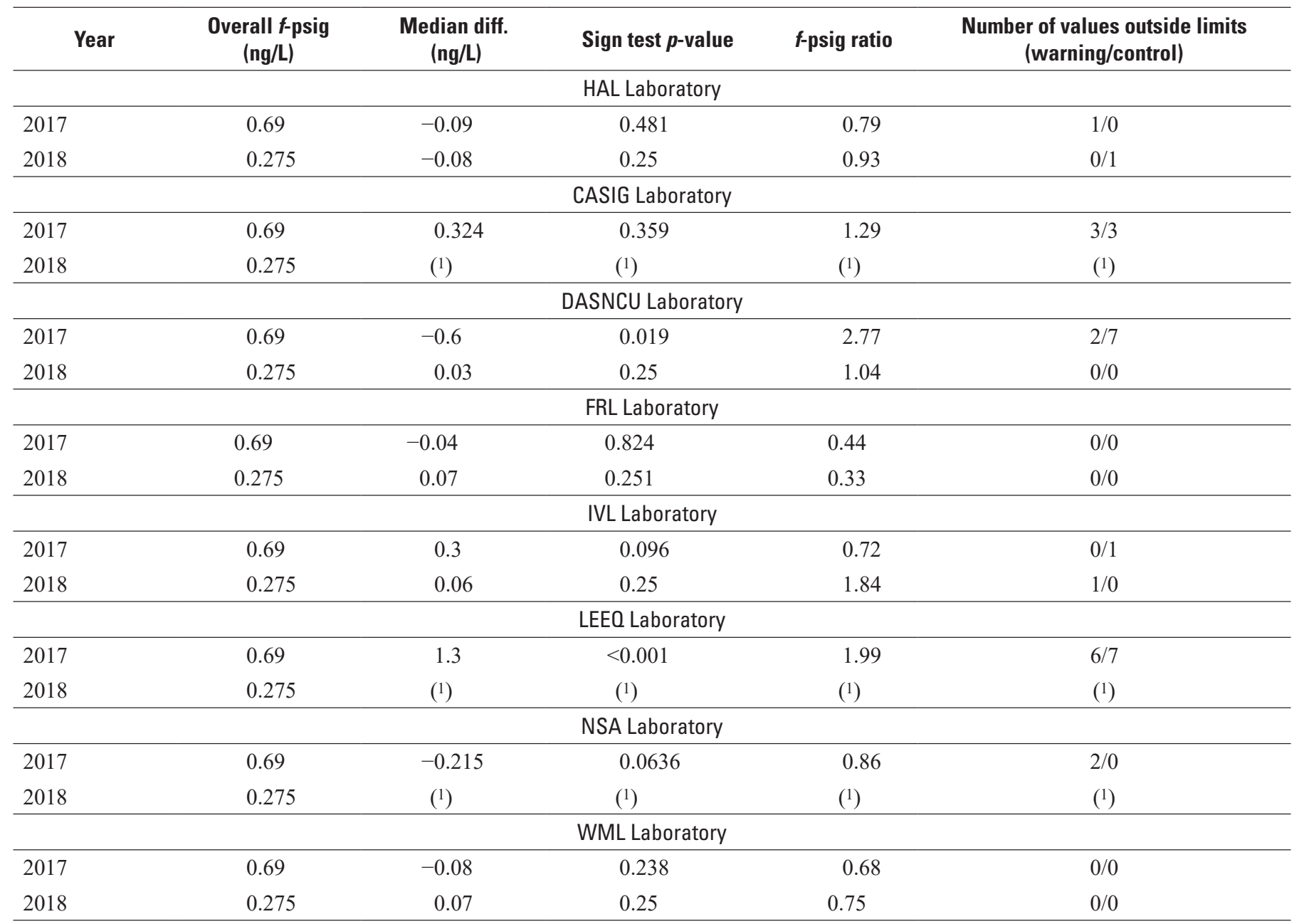

1Laboratory did not participate in limited 2018 interlaboratory-comparison program.

Annual overall $f$-psig values were $0.690 \mathrm{ng} / \mathrm{L}$ and $0.275 \mathrm{ng} / \mathrm{L}$ for 2017 and 2018, respectively, for the concentration ranges indicated by the MPVs in table 12 . Results in table 13 indicate that the HAL's performance was similar to that of FRL, NSA, and WML during the study period. The HAL's total $\mathrm{Hg}$ analyses were characterized by less variability than overall in 2017 and 2018 with $f$-psig ratios of 79 and 93 percent, respectively. The HAL results indicated small median differences $(-0.090$ and $0.080 \mathrm{ng} / \mathrm{L})$ that were not statistically significant from zero $(p=0.481$ and 0.250$)$ during 2017 and 2018, respectively (table 13). Median differences from the MPVs were less than or equal to the second percentile of all weekly MDN total $\mathrm{Hg}$ concentrations of $1.41 \mathrm{ng} / \mathrm{L}$. Therefore, the annual bias estimates for all of the laboratories are negligible compared to total $\mathrm{Hg}$ concentrations determined by the MDN during 2016 and 2018 (Robert Larson, NADP Program Office, Wisconsin State Laboratory of Hygiene, written commun., 2019). 
Table 14. Number of total mercury determinations greater than the method detection limits for blank samples, Mercury Deposition Network interlaboratory comparison program, 2017-18.

[Four determinations per year per laboratory; HAL, Mercury Analytical Laboratory at Eurofins Frontier Global Sciences, Inc.; CASIG, Chinese Academy of Sciences, Institute of Geochemistry; DASNCU, Department of Atmospheric Sciences, National Central University (Taiwan); FRL, Flett Research, Ltd.; IVL, Swedish Environmental Research Institute; LEEQ, Quebec Laboratory of Environmental Testing; NSA, North Shore Analytical, Inc.; WML, U.S. Geological Survey Wisconsin Mercury Laboratory; ng/L, nanogram per liter; N/A, not applicable]

\begin{tabular}{|c|c|c|c|c|c|c|c|}
\hline HAL & CASIG1 & DASNCU & FRL & IVL & LEE01 & NSA & WML \\
\hline \multicolumn{8}{|c|}{2017} \\
\hline 0 & 4 & 1 & 0 & 0 & 2 & 0 & 1 \\
\hline 0 & $\mathrm{~N} / \mathrm{A}$ & 1 & 2 & 3 & N/A & $\mathrm{N} / \mathrm{A}$ & 3 \\
\hline \multicolumn{8}{|c|}{ Minimum reporting limits (ng/L) } \\
\hline
\end{tabular}

${ }^{1}$ Laboratory did not participate in limited 2018 interlaboratory-comparison program.

\section{Results for Blanks}

Interlaboratory comparison results for 2017-18 blank samples are shown in table 14. Four blind blank samples were shipped to each laboratory annually. Minimum reporting levels (MRLs) vary between laboratories and were less than or equal to $0.10 \mathrm{ng} / \mathrm{L}$ during $2017-18$. The HAL had no values reported above the detection limit of $0.08 \mathrm{ng} / \mathrm{L}$ for blank samples.

As shown for results in previous years, results of blank analyses indicate that HAL Hg contamination during the study period was low (Wetherbee and Martin, 2016b). Therefore, most Hg contamination in MDN samples, which was estimated using the system blanks, was likely introduced in the field.

\section{Summary}

The U.S. Geological Survey (USGS) used three programs to provide external quality assurance monitoring for the National Atmospheric Deposition Program's (NADP) National Trends Network (NTN) and two programs to provide external quality assurance monitoring for the NADP Mercury Deposition Network (MDN) during 2017-18. The field audit program assessed the effects of onsite exposure, sample handling, and shipping on the chemistry of NTN samples; the system blank program assessed the same effects for MDN samples. Two interlaboratory comparison programs assessed the bias and variability of the chemical analysis data from the Central Analytical Laboratory (CAL), Mercury Analytical Laboratory (HAL), and other participating laboratories that analyze precipitation samples for major ions, nutrients, and trace levels of mercury $(\mathrm{Hg})$. A colocated sampler program was used to quantify the variability of NADP data collected with N-CON sample collectors. During 2018, the CAL moved from the Illinois State Water Survey (ICAL) to the Wisconsin Laboratory of Hygiene (WCAL). The field audit and system blank programs were not operated in 2018 and the MDN interlaboratory comparison program was reduced in scope during 2018 both to provide support and avoid potential complications for the CAL transition. Due to the change in CAL operations during the study period, ICAL and WCAL performance is compared in this report.

\section{National Trends Network}

Field audit results for 2017-18 indicate that network maximum contamination levels for calcium, magnesium, sodium, ammonium, and chloride, in NTN samples, have not changed appreciably since 2014, but the Network Maximum Contamination Level (NMCL) for potassium decreased approximately $-0.003 \mathrm{mg} / \mathrm{L}$. The NMCLs for nitrate and sulfate increased by approximately $0.01 \mathrm{mg} / \mathrm{L}(2015-17)$ and then decreased again (2016-18) to levels lower than those measured during 2014-16. Variable levels of sample contamination over the past 10 years are small in terms of their absolute concentrations. However, the 2016-18 calcium, magnesium, sodium, and potassium NMCLs were equivalent to the 22nd, 26th, 20th, and 13th percentile concentrations, respectively, in NADP samples during the same period. The NMCLs for chloride $(0.022 \mathrm{mg} / \mathrm{L})$, nitrate $(0.071 \mathrm{mg} / \mathrm{L})$, and sulfate $(0.054 \mathrm{mg} / \mathrm{L})$, were at the 9 th, 2 nd, and 2 nd NTN concentration percentiles, respectively. This program also estimated the maximum loss of ammonium, nitrate, and hydrogen ion in weekly NTN samples. Ammonium loss increased from $0.010 \mathrm{mg} / \mathrm{L}$ (2014-2016) to $0.020 \mathrm{mg} / \mathrm{L}$ (2015-2017), which is approximately 2.2 times the $2018 \mathrm{MDL}$ for $(0.009 \mathrm{mg} / \mathrm{L})$. Hydrogen ion maximum loss was 2.50 microequivalents per liter ( $\mu \mathrm{eq} / \mathrm{L})$, which has not changed since 2014.

During 2017, statistically significant bias was observed for ICAL (calcium, potassium, and ammonium) and WCAL (chloride) results. During 2018, statistically significant bias was identified for ICAL (calcium and potassium) and WCAL (chloride). The ECST, ICAL, AMEC/WOOD, RTI, and 
WCAL laboratories had comparable, low overall variability among the participating laboratories during $2017-18$ as indicated by most $f$-psig ratios less than 100 .

No results were reported above analytical detection limits for blank samples for the ECST, NILU, RTI, UNAM, and AMEC/WOOD laboratories during 2017-18. The ACAP laboratory reported detections for all constituents in 2018 for at least two blanks per analyte. The ICAL reported detections for potassium and ammonium in two of four blanks analyzed in 2017 and for calcium (1), magnesium (1), potassium (2), ammonium (1), and chloride (1) in 2018. The ECST laboratory reported no detected analytes in blanks for 2017 and detections for calcium (1), sodium (1), and potassium (2) in 2018. The MOECC laboratory reported detections in blanks for calcium (4), potassium (2), ammonium (5), chloride (2), nitrate (3), and sulfate (2) during 2017-18. The NRS laboratory reported detections in blanks for calcium (2), magnesium (1), sodium (1), potassium (4), ammonium (1), chloride (2), nitrate (3), and sulfate (2) for 2017-18 combined. The WCAL reported a detection for magnesium in a blank during 2018 and analyzed no blanks in 2017.

Analyte determinations that exceeded statistical control limits ( $\pm 3 f$-pseudosigma) for ICAL during 2017-18 include ammonium (1), nitrate (2), sulfate (1), specific conductance (7), and hydrogen ion (5). Analyte determinations that exceeded the control limits for WCAL during 2017-18 include calcium (1), magnesium (1), sodium (1), potassium (1), chloride (1), bromide (1), nitrate (10), sulfate (3), and hydrogen ion (21). The interlaboratory-comparison program results indicate differences in performance for ICAL and WCAL primarily for analysis of nitrate, specific conductance, and $\mathrm{pH}$. However, in an independent study in 2018, results for 75 spiked natural matrix split samples analyzed by the ICAL and WCAL revealed median absolute percent differences less than 10 percent for all analytes except potassium (12 percent). Furthermore, the Readiness Verification Plan (RVP) results indicated a negative bias for WCAL results relative to ICAL results for nitrate and hydrogen ion concentrations, which is the opposite of the comparison presented in this report.

Weekly wet-deposition data for colocated N-CON collectors at NTN sites CO11 and $11 \mathrm{CO}$ at the Arvada Community Gardens were collected in water years 2017 and 2018. Concentration differences for the paired weekly samples were calculated to evaluate overall variability in NTN measurements. The median weekly absolute concentration differences were small and ranged $0.000-0.005 \mathrm{mg} / \mathrm{L}$ for calcium, magnesium, sodium and potassium (cations), and $0.003-0.020 \mathrm{mg} / \mathrm{L}$ for chloride, nitrate, and sulfate (anions). Median absolute differences for ammonium $(0.00-0.022 \mathrm{mg} / \mathrm{L})$; and hydrogen ion $(0.009-0.010 \mu \mathrm{eq} / \mathrm{L})$ and specific conductance $(0.3-1.0 \mu \mathrm{S} / \mathrm{cm})$ were also considered small. Median weekly absolute percent differences ranged 7-22 percent for cations, 4-10 percent for anions, 6-9 percent for ammonium, and 9.2-32 percent for hydrogen ion. Median weekly absolute percent differences for sample volume catch were low at 4-5 percent.
Annual deposition absolute percent differences (APD) ranged 8-18 percent for calcium and were zero for magnesium, sodium, and potassium. Ammonium annual deposition APD ranged 0-12 percent. Ranges of annual deposition APD for anions were: chloride (12-29 percent); nitrate (2-15 percent); and sulfate ( $0-7$ percent). Annual hydrogen-ion deposition APD ranged 0-51 percent. Hydrogen-ion concentrations were low with 35 of the $46 \mathrm{pH}$ measurements greater than $\mathrm{pH}=6$, and percent differences of small hydrogen-ion concentrations were relatively large.

\section{Mercury Deposition Network}

The MDN NMCL for total Hg decreased from $1.098 \mathrm{ng} / \mathrm{L}$ during 2014-16 to $1.023 \mathrm{ng} / \mathrm{L}$ during 2015-17. Thus, the maximum contamination in MDN samples during 2015-17 was not greater than $1.023 \mathrm{ng} / \mathrm{L}$ with 90 -percent confidence, and no more than 10 percent of the MDN samples had contamination concentrations exceeding $1.023 \mathrm{ng} / \mathrm{L}$ with 90 -percent confidence. This concentration is approximately equal to the first percentile of all MDN weekly Hg concentrations from 2016 to 18 . The maximum estimated contaminant mass per sample increased slightly from $0.094 \mathrm{ng} \mathrm{Hg}$ during 2014-16 to 0.101 ng Hg during 2015-17.

The HAL's control chart for the 2017-18 interlaboratory comparison analyses shows that all results are within statistical control ( $\pm 3 f$-psig) except for one result for solution MP4 in the fourth quarter of 2018. One result for MP2 was outside the positive warning limit ( $+2 f$-psig) during 2017. No bias in the HAL results was evident from the control chart. The HAL's total $\mathrm{Hg}$ analyses were characterized by less variability than overall in 2017 and 2018 with $f$-psig ratios of 79 and 93 percent, respectively. The HAL results indicated small median differences $(-0.090$ and $0.080 \mathrm{ng} / \mathrm{L})$ that were not significantly different from zero $(p=0.481$ and 0.250$)$ during 2017 and 2018, respectively. Median differences from the MPVs were less than or equal to the second percentile of all weekly MDN total $\mathrm{Hg}$ concentrations of $1.41 \mathrm{ng} / \mathrm{L}$. The HAL had no values reported above the detection limit of $0.08 \mathrm{ng} / \mathrm{L}$ for blank samples.

\section{References Cited}

Gibbons, R.D., and Coleman, D.E., 2001, Statistical methods for detection and quantification of environmental contamination: New York, John Wiley \& Sons, p. 139-146.

Hahn, G.J., and Meeker, W.Q., 1991, Statistical intervals-A guide for practitioners: New York, John Wiley \& Sons, 392 p. [Also available at https://doi.org/10.1002/ 9780470316771.] 
Helsel, D.R., 2012, Statistics for censored environmental data using Minitab and R 2nd ed.: Hoboken, N.J., John Wiley \& Sons, p. 70-77.

Hoaglin, D.C., Mosteller, Frederick, and Tukey, J.W., 1983, Understanding robust and exploratory data analysis: New York, John Wiley \& Sons, p. 38-41.

Kanji, G.K., 2006, 100 statistical tests 3rd ed.: New Delhi, Sage Publications Ltd., 242 p. [Also available at https://doi.org/10.4135/9781849208499.]

Latysh, N.E., and Wetherbee, G.A., 2005, External quality assurance programs managed by the U.S. Geological Survey in support of the National Atmospheric Deposition Program/National Trends Network: U.S. Geological Survey Open-File Report 2005-1024, 66 p., accessed January 31, 2018 at https://pubs.er.usgs.gov/publication/ofr20051024.

Latysh, N.E., and Wetherbee, G.A., 2007, External quality assurance programs managed by the U.S. Geological Survey in support of the National Atmospheric Deposition Program/Mercury Deposition Network: U.S. Geological Survey Open-File Report 2007-1170, 33 p., accessed January 31, 2018, at https://pubs.er.usgs.gov/publication/ ofr20071170.

Morris, K., Mast, A., Clow, D., Wetherbee, G., Baron, J., Taipale, C., Blett, T., Gay, D., and Heath, J., 2014, 2012 Monitoring and tracking wet nitrogen deposition at Rocky Mountain National Park: National Park Service, Natural Resource Report NPS/NRSS/ARD/NR—2014/757, 24 p., accessed January 31, 2018, at https://www.nature.nps.gov/ publications/nrpm/nrr.cfm\#.

R Development Core Team, 2018, R-A language and environment for statistical computing: Vienna, Austria, R Foundation for Statistical Computing, ISBN 3-900051-07-0, accessed December 20, 2018, at http:/www.R-project.org/.

SAS Institute, Inc., 2016, SAS software version 9.4, Copyright (C) 2016: Cary, NC, USA, SAS Institute Inc.

Tchobanoglous, George, and Schroeder, E.D., 1987, Water quality - Characteristics, modeling, modification: Reading, Mass., Addison-Wesley Publishing Company, Inc., p. 204-207.

U.S. Environmental Protection Agency, 2002, Method 1631, revision E-Mercury in water by oxidation, purge and trap, and cold vapor atomic fluorescence spectrometry: U.S. Environmental Protection Agency, Office of Water report EPA-821-R-02-019, 38 p., accessed May 6, 2014, at https://water.epa.gov/scitech/methods/cwa/metals/mercury/ upload/2007_07_10_methods_method_mercury_1631.pdf
U.S. Geological Survey, 2002, Processing of Water Samples (edited by Wilde, F.D.): U.S. Geological Survey Techniques of Water-Resources Investigations, book 9; chap A5, p. 90, accessed April 15, 2020, at https://doi.org/10.3133/ twri09A5.

Wetherbee, G.A., 2020, U.S. Geological Survey Precipitation Chemistry Quality Assurance Project Data 2017-2018: U.S. Geological Survey data release, https://doi.org/10.5066/ P9ZKXD8N.

Wetherbee, G.A., 2019, Data for the U.S. Geological Survey Precipitation Chemistry Quality Assurance Project for the National Atmospheric Deposition Program, 1978-2017: U.S. Geological Survey data release, https://doi.org/ 10.5066/P94RC4GD.

Wetherbee, G.A., 2017, Precipitation collector bias and its effects on temporal trends and spatial variability in National Atmospheric Deposition Program/National Trends Network data: Environmental Pollution, v. 223, p. 90-101. [Also available at https://doi.org/10.1016/j.envpol.2016.12.036.]

Wetherbee, G.A., Latysh, N.E., and Burke, K.P., 2005a, External quality assurance results for the National Atmospheric Deposition Program/National Trends Network, 2002-03: U.S. Geological Survey Scientific Investigations Report 2005-5061, 59 p., accessed January 31, 2018, at https://pubs.er.usgs.gov/publication/sir20055061.

Wetherbee, G.A., Latysh, N.E., and Gordon, J.D., 2005b, Spatial and temporal variability of the overall error of National Atmospheric Deposition Program measurements determined by the USGS colocated-sampler program, water years 1989-2001: Environmental Pollution, v. 135, no. 3, p. 407-418. [Also available at https://doi.org/10.1016/ j.envpol.2004.11.014.]

Wetherbee, G.A., Latysh, N.E., and Greene, S.M., 2006, External quality assurance results for the National Atmospheric Deposition Program/National Trends Network, 2004: U.S. Geological Survey Scientific Investigations Report 2006-5067, 52 p., accessed January 31, 2018, at https://pubs.er.usgs.gov/publication/sir20065067.

Wetherbee, G.A., Latysh, N.E., Greene, S.M., and Chesney, T.A., 2009, U.S. Geological Survey external qualityassurance program results reported to the National Atmospheric Deposition Program/National Trends Network and Mercury Deposition Network for 2005-06: Champaign, Ill., National Atmospheric Deposition Program Quality Assurance Report 2009-01, Illinois State Water Survey Data/Case Study 2009-01, 54 p., accessed April 15, 2020, at http://nadp.slh.wisc.edu/lib/qa/nadp_qa0506.pdf. 
Wetherbee, G.A., Latysh, N.E., Greene, S.M., and Chesney, T.A., 2010, U.S. Geological Survey external qualityassurance project report to the National Atmospheric Deposition Program/National Trends Network and Mercury Deposition Network, 2007-08: Champaign, Ill., National Atmospheric Deposition Program Quality Assurance Report 2010-01 and Illinois State Water Survey Miscellaneous Publication 190, 82 p., accessed April 15, 2020, at http://nadp.slh.wisc.edu/lib/qa/nadp_qa0708.pdf.

Wetherbee, G.A., Martin, R.A., Rhodes, M.F., and Chesney, T.A., 2013, External quality-assurance project report for the National Atmospheric Deposition Program/National Trends Network and Mercury Deposition Network for 2009-2010: U.S. Geological Survey Scientific Investigations Report 2013-5147, 53 p., accessed April 15, 2020, at https://pubs.er.usgs.gov/publication/sir20135147.

Wetherbee, G.A., and Rhodes, M.F., 2013, Effects of equipment performance on data quality from the National Atmospheric Deposition Program/National Trends Network and the Mercury Deposition Network: U.S. Geological Survey Open-File Report 2013-1031, 53 p., accessed January 31, 2018, at https://pubs.er.usgs.gov/publication/ ofr20131031.
Wetherbee, G.A., and Martin, R.A., 2016a, Updated operational protocols for the U.S. Geological Survey Precipitation Chemistry Quality Assurance Project in Support of the National Atmospheric Deposition Program: U.S. Geological Survey Open-File Report 2016-1213, 18 p., accessed January 31, 2018, at https://pubs.er.usgs.gov/publication/ ofr20161213.

Wetherbee, G.A., and Martin, R.A., 2016b, External quality assurance project report for the National Atmospheric Deposition Program's National Trends Network and Mercury Deposition Network, 2013-14: U.S. Geological Survey Scientific Investigations Report 2016-5069, 22 p., accessed April 15, 2020, at https://pubs.er.usgs.gov/ publication/sir20165069.

Wetherbee, G.A., and Martin, R.A., 2018, External quality assurance project report for the National Atmospheric Deposition Program's National Trends Network and Mercury Deposition Network, 2015-16: U.S. Geological Survey Scientific Investigations Report 2018-5034, 25 p., accessed September 20, 2019, at https://pubs.er.usgs.gov/ publication/sir20185034.

Wisconsin State Laboratory of Hygiene, 2019, National Trends Network site operations manual, NADP Program Office Revision Date: 5/1/2019, accessed April 15, 2020, at http://nadp.slh.wisc.edu/siteops/lib/ntn/NTN-2000 Operations_Manual_v_3-0.pdf. 

Publishing support provided by the Science Publishing Network, Denver Publishing Service Center and Rolla Publishing Service Center

For more information concerning the research in this report, contact: Director, Observing Systems Division Buildings 2101, 2204 HIF

Hydrologic Instrumentation Facility, Stennis Space Center, MS 39529 (228) 688-1501

Or visit the Precipitation Chemistry Quality Assurance Project website at https://bqs.usgs.gov/PCQA/ 

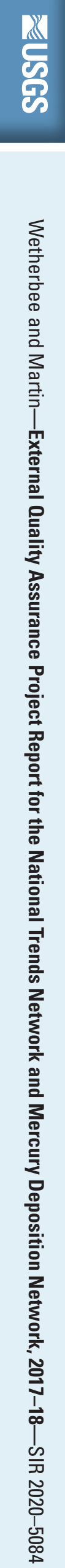